\title{
Liquid-Chromatographic Methods for Carboxylic Acids in Biological Samples
}

\author{
Takuya Fujiwara, Ryoto Inoue, Takuma Ohtawa and Makoto Tsunoda *(D) \\ Graduate School of Pharmaceutial Sciences, The University of Tokyo, Tokyo 1130033, Japan; \\ taku1729@gmail.com (T.F.); ryoino888@gmail.com (R.I.); tawashi994865@gmail.com (T.O.) \\ * Correspondence: makotot@mol.f.u-tokyo.ac.jp; Tel.: +81-3-5841-4761
}

Academic Editors: Constantinos K. Zacharis and Paraskevas D. Tzanavaras

Received: 21 September 2020; Accepted: 14 October 2020; Published: 22 October 2020

\begin{abstract}
Carboxyl-bearing low-molecular-weight compounds such as keto acids, fatty acids, and other organic acids are involved in a myriad of metabolic pathways owing to their high polarity and solubility in biological fluids. Various disease areas such as cancer, myeloid leukemia, heart disease, liver disease, and lifestyle diseases (obesity and diabetes) were found to be related to certain metabolic pathways and changes in the concentrations of the compounds involved in those pathways. Therefore, the quantification of such compounds provides useful information pertaining to diagnosis, pathological conditions, and disease mechanisms, spurring the development of numerous analytical methods for this purpose. This review article addresses analytical methods for the quantification of carboxylic acids, which were classified into fatty acids, tricarboxylic acid cycle and glycolysis-related compounds, amino acid metabolites, perfluorinated carboxylic acids, $\alpha$-keto acids and their metabolites, thiazole-containing carboxylic acids, and miscellaneous, in biological samples from 2000 to date. Methods involving liquid chromatography coupled with ultraviolet, fluorescence, mass spectrometry, and electrochemical detection were summarized.
\end{abstract}

Keywords: fluorescence; mass spectrometry; fatty acids; perfluorinated carboxylic acids; $\alpha$-keto acids

\section{Introduction}

Quantification of low-molecular-weight compounds, as exemplified by metabolomics studies, has become increasingly important in the life sciences. Metabolite analysis provides metabolic and biochemical status of particular biological systems and valuable insights into disease development and diagnosis [1-6]. There are numerous classes of low-molecular-weight compounds, and they are categorized based on their functional groups, including amine, thiol, and carboxylic groups. Low-molecular-weight carboxylic acids are involved in various metabolic pathways. For example, the tricarboxylic acid (TCA) cycle, which is the principal energy-producing process in cells, involves nine carboxylic acid compounds. Fatty acids are integral components of lipids, and consist of carboxylic acids with long aliphatic chains.

Hence, highly sensitive and selective methods for the determination of biologically important carboxylic acids are required for biological investigations, and, thus far, numerous analytical methods have been developed. For selective determination, solid-phase extraction or solvent extraction pretreatment is commonly performed, followed by separation techniques such as liquid chromatography (LC), gas chromatography (GC), and capillary electrophoresis. The choice of detection method is important for trace amounts of carboxylic acids in biological samples. Ultraviolet absorbance detection is rarely implemented due to the absence of chromophores in carboxylic acids. Fluorescence detection following derivatization and mass spectrometry has the advantage of high sensitivity.

This review focuses on analytical methods for carboxylic acids developed since 2000 until March 2020. The aim of this review is to summarize pretreatment and LC separation methods for carboxylic 
acids in biological samples, such as blood, plasma, urine, and tissue and thus provide a reference for further studies. The review is arranged according to compound classes, namely, fatty acids, TCA cycle and glycolysis-related compounds, amino acid metabolites, perfluorinated carboxylic acids (PFCAs), $\alpha$-keto acids and their metabolites, thiazole-containing carboxylic acids, and miscellaneous. Detailed analytical conditions for each carboxylic acid class are summarized in Tables 1-7. 
Table 1. Analytical methods for fatty acids in biological samples.

\begin{tabular}{|c|c|c|c|c|c|c|c|c|}
\hline Target Compounds & Biological Sample & Sample Treatment & Derivatization Reagent & Separation Mode & Detection Method & LOD & Recovery & Ref. \\
\hline 7 Fatty acids & Human serum & Acid extraction & APF & RPLC & FL: $467 / 512 \mathrm{~nm}$ & $0.1-6.4 \mathrm{nM}$ & $93-105 \%$ & [7] \\
\hline 3 Fatty acids & Human plasma & Acid extraction & NOEPES & RPLC & FL: $235 / 366 \mathrm{~nm}$ & $56 \mathrm{fmol}$ & - & [8] \\
\hline 6 Fatty acids & Human plasma & Acid extraction & HEC & RPLC & FL: $293 / 365 \mathrm{~nm}$ & $38-57 \mathrm{fmol}$ & $102-106 \%$ & [9] \\
\hline 6 Fatty acids & Human plasma & Acid extraction & HEC & RPLC & FL: $335 / 365 \mathrm{~nm}$ & $45-68 \mathrm{fmol}$ & $102-105 \%$ & [10] \\
\hline 5 Fatty acids & Human serum & Acid extraction & DBD-ED & RPLC & FL: $450 / 560 \mathrm{~nm}$ & $2.29-4.75 \mathrm{fmol}$ & $108-113 \%$ & [11] \\
\hline 8 Fatty acids & Rat plasma & Acid extraction & DBD-ED & RPLC & FL: $450 / 560 \mathrm{~nm}$ & - & - & [12] \\
\hline 4 Epoxyeicosatrienoic acids & Bovine endothelial cells & Solid phase extraction & NT & RPLC & FL: $259 / 395 \mathrm{~nm}$ & $<2 \mathrm{pg}$ & $83-89 \%$ & [13] \\
\hline 25 Fatty acids & Mouse serum & Acid extraction & AMPP & RPLC & MS/MS & $50-100 \mathrm{fg}$ (LOQ) & - & [14] \\
\hline 11 Fatty acids & $\begin{array}{l}\text { Mouse serum, bronchial } \\
\text { epithelial cells }\end{array}$ & Solid phase extraction & AMPP & RPLC & $\mathrm{MS} / \mathrm{MS}$ & 200-900 fg (LOQ) & - & [15] \\
\hline 20 Fatty acids & Breast cancer cells & Solvent extraction & Aminoxy TMT & RPLC & MS/MS & $40 \mathrm{fmol}$ & - & [16] \\
\hline 8 Fatty acids & Rat plasma & Acid extraction & DBD-PZ-NH ${ }_{2}$ & RPLC & MS & $<0.1 \mu \mathrm{M}$ & - & [17] \\
\hline \multirow[t]{3}{*}{9 Fatty acids } & Rat plasma & Solvent extraction & DAABD-AE & RPLC & MS & $6.5-21 \mathrm{fmol}$ & - & [18] \\
\hline & & & MePZBD-AE & RPLC & MS & $8.8-32 \mathrm{fmol}$ & - & [18] \\
\hline & & & APZBD-NHMe & RPLC & MS & $35-150 \mathrm{fmol}$ & - & [18] \\
\hline 56 Fatty acids & Human plasma & Centrifugation & Choline & HILIC & MS & $50 \mathrm{ng} / \mathrm{mL}$ & - & [19] \\
\hline $\begin{array}{l}38 \text { Fatty acids, } \\
\text { acylcarnitines }\end{array}$ & Human plasma & Centrifugation & Dansyl-hydrazine & RPLC & MS/MS & $76-152 \mathrm{pM}$ & - & {$[20]$} \\
\hline 18 Fatty acids & Human urine & Solid phase extraction & $\mathrm{d}_{0}-\mathrm{DMPP}, \mathrm{d}_{6}$-DMPP & RPLC & MS/MS & 5-15 pM & - & [21] \\
\hline 60 Fatty acids & Human serum & Acid extraction & DMED, $\mathrm{d}_{4}$-DMED & RPLC & MS & - & - & [22] \\
\hline 6 Fatty acids & Human blood & Acid extraction & None & RPLC & MS & low pg range & - & [23] \\
\hline 4 Fatty acids & Human serum, plasma & Solvent extraction & None & RPLC & ECD & $50 \mathrm{pmol}$ & $92-102 \%$ & [24] \\
\hline 6 Fatty acids & Human plasma & Solvent extraction & None & RPLC & ECD & $50 \mathrm{pmol}$ & $92-102 \%$ & [25] \\
\hline 11 Fatty acids & Human plasma & Solvent extraction & AEMP, NAPP & RPLC & $\begin{array}{l}\text { Electrogenerated } \\
\text { chemiluminescence }\end{array}$ & $70 \mathrm{fmol}$ & - & [26] \\
\hline
\end{tabular}

APF: 6-oxy-(acetyl piperazine)fluorescein, NOEPES: 2-(2-naphoxy)ethyl 2-(piperidino)ethanesulfonate, HEC: 9-(2-hydroxyethyl)-carbazole, DBD-ED: 4-N,N-dimethylaminosulfonyl-
7- $N$-(2-aminoethyl)amino-2,1,3-benzoxadiazole, NT: 2-(2,3-naphthalimino)ethyl trifluoromethanesulfonate, AMPP: $N$-(4-aminomethylphenyl)pyridinium, AminoxyTMT: aminoxy tandem mass tags, DBD-PZ- $\mathrm{NH}_{2}$ : 7-(N,N-dimethylaminosulfonyl)-4-(aminoethyl)piperazino-2,1,3-benzoxadiazole, DAABD-AE: 4-[2-(N,N-dimethylamino)ethylaminosulfonyl]7-(2-aminoethylamino)-2,1,3-benzoxadiazole, MePZBD-AE: [4-(4- $N$-methyl)piperazinosulfonyl]-7-(2-aminoethylamino)-2,1,3-benzoxadiazole, APZBD-NHMe: [4-(4-N-aminoethyl) piperazinosulfonyl]-7-methylamino-2,1,3-benzoxadiazole, DMPP: 2,4-dimethoxy-6-piperazin-1-yl pyrimidine, DMED: 2-dimethylaminoethylamine, AEMP: 2-(2-aminoethyl)-1methylpyrrolidine, NAPP: N-(3-aminopropyl)pyrrolidine. 
Table 2. Analytical methods for TCA cycle and glycolysis-related compounds in biological samples.

\begin{tabular}{|c|c|c|c|c|c|c|c|c|}
\hline Target Compounds & Biological Sample & Sample Treatment & Derivatization Reagent & Separation Mode & Detection Method & LOD & Recovery & Ref. \\
\hline Fumaric acid & Rat liver, spleen and urine & Centrifugation & None & RPLC & PDA: $215 \mathrm{~nm}$ & $0.01 \mu \mathrm{g}$ & $89-92 \%$ & [27] \\
\hline Maleic acid & Rat serum and urine & Centrifugation & None & RPLC & MS/MS & $0.2 \mu \mathrm{g} / \mathrm{L}$ & $94-111 \%$ & [28] \\
\hline Methylmalonic acid & Human plasma & Centrifugation & None & HILIC & MS & $0.03 \mu \mathrm{M}$ & $90-93 \%$ & [29] \\
\hline Lactic acid & Human urine and saliva & Centrifugation & 9-CMA & RPLC & $\begin{array}{l}\text { UV: } 365 \mathrm{~nm}, \\
\text { FL: } 365 / 410 \mathrm{~nm}\end{array}$ & $50 \mathrm{nM}$ & $92-106 \%$ & [30] \\
\hline Oxalic acid & Mouse urine and hepatocyte & Centrifugation & None & Ion exclusion chromatography & MS/MS & $2 \mu \mathrm{M}$ & - & [31] \\
\hline 6 TCA metabolites & Rat urine & Centrifugation & DBD-PZ & RPLC & FL: $450 / 560 \mathrm{~nm}$ & 2-15 fmol & $80-96 \%$ & [32] \\
\hline 9 Organic acids & Yeast & Centrifugation & None & Ion exclusion chromatography & UV: $210 \mathrm{~nm}$ & $0.6-29.3 \mathrm{~g} / \mathrm{L}$ & $98-103 \%$ & [33] \\
\hline 32 Organic acids & Human urine & Solvent extraction & None & Ion exclusion chromatography & UV: $220 \mathrm{~nm}$ & $0.002-2.2 \mathrm{~g} / \mathrm{L}$ & - & [34] \\
\hline 13 Organic acids & Mouse urine & Centrifugation & 1-Pyrene methylamine & RPLC & FL: $345 / 375,345 / 475 \mathrm{~nm}$ & 4-22 fmol & - & [35] \\
\hline 30 Organic acids & Mouse serum, urine, and tissue & Centrifugation & None & HILIC, Ion pair RPLC & MS/MS & $<5 \mu \mathrm{M}$ & - & [36] \\
\hline 59 Organic acids & Human melanoma cells & Centrifugation & Phenylhdrazine & Ion pair RPLC & MS & - & - & [37] \\
\hline 138 Organic acids & Yeast & Centrifugation & None & RPLC & MS/MS & $0.001-3.7 \mu \mathrm{M}$ & - & [38] \\
\hline TCA metabolites & Human red blood cell & Centrifugation & None & RPLC & MS & - & - & [39] \\
\hline
\end{tabular}

9-CMA: 9-chloromethyl anthracene, DBD-PZ: 7-(N,N-dimethylaminosulfonyl)-4-piperazino-2,1,3-benzoxadiazole.

Table 3. Analytical methods for amino acid metabolites in biological samples.

\begin{tabular}{|c|c|c|c|c|c|c|c|c|}
\hline Target Compounds & Biological Sample & Sample Treatment & Derivatization Reagent & Separation Mode & Detection Method & LOD & Recovery & Ref. \\
\hline Kinurenic acid & Rat plasma & Centrifugation & None & RPLC & FL: $251 / 398 \mathrm{~nm}$ & $0.16 \mathrm{nM}$ & $97-98 \%$ & [40] \\
\hline 3 Trp metabolites & Mouse plasma and brain & Centrifugation & None & RPLC & UV, FL & $0.03-1.33 \mu \mathrm{M}$ & $83-116 \%$ & [41] \\
\hline 6 Trp metabolites & Pig urine, plasma & Centrifugation & None & RPLC & MS & $10-100 \mathrm{ng} / \mathrm{mL}$ (LOQ) & - & [42] \\
\hline Glycated Trp & Chicken plasma & Solvent extraction & None & RPLC & MS & - & - & [43] \\
\hline PHP-ТH $\beta C$ & Chicken plasma & Cation-exchange resin & None & RPLC & MS & - & - & [44] \\
\hline $\begin{array}{l}5 \text { Trp and Tyr } \\
\text { metabolites }\end{array}$ & Human urine & Centrifugation & None & RPLC & $\begin{array}{l}\text { UV: } 220,280 \mathrm{~nm} \text {, FL: } \\
280 / 350,315 / 425 \mathrm{~nm}\end{array}$ & - & - & [45] \\
\hline DOPAC, HVA & Rat kidney & Microdialysis & Ethylenediamine & $\begin{array}{c}\text { Ion exchange } \\
\text { chromatography }\end{array}$ & FL: 417/495 nm & $50,100 \mathrm{fmol}$ & - & [46] \\
\hline \multirow{3}{*}{$\begin{array}{l}\text { Nicotinic acid } \\
\text { Glutaric acid, 3-HG } \\
64 \text { amino acid } \\
\text { derivatives }\end{array}$} & Human plasma & Solvent extraction & None & RPLC & MS/MS & $6.57 \mathrm{ng} / \mathrm{mL}$ (LOQ) & $70-72 \%$ & [47] \\
\hline & Human urine & Centrifugation & DAABD-AE & RPLC & MS/MS & $20-25 \mathrm{nM}$ & $94-121 \%$ & [48] \\
\hline & $\begin{array}{l}\text { Human urine, pancreatic } \\
\text { cancer cells }\end{array}$ & Centrifugation & DmPABr & RPLC & MS/MS & $0.11-2192 \mathrm{nM}$ & - & [49] \\
\hline
\end{tabular}

PHP-THßC: (1R, 3S)-1-(D-gluco-1, 2, 3, 4, 5-pentahydroxypentyl)-1,2,3,4-tetrahydro- $\beta$-carboline-3-carboxylic acid, DOPAC: 3,4-dihydroxyphenylacetic acid, HVA: homovanillic acid, 3-HG:

3-hydroxyglutaric acid, DAABD-AE: 4-[2-(N,N-dimethylamino)ethylaminosulfonyl]-7-(2-aminoethylamino)-2,1,3-benzoxadiazole, DmPABr: dimethylaminophenacyl bromide. 
Table 4. Analytical methods for perfluorinated carboxylic acids (PFCAs) in biological samples.

\begin{tabular}{|c|c|c|c|c|c|c|c|c|}
\hline Target Compounds & Biological Sample & Sample Treatment & Derivatization Reagent & Separation Mode & Detection Method & LOD & Recovery & Ref. \\
\hline 3 PFASs & Human tissues and blood & Solid phase extraction & None & RPLC & MS & $3 \mu \mathrm{g} / \mathrm{L}$ & $80-101 \%$ & [50] \\
\hline 10 PFASs & Two bivalves shells, soft tissues & Solid phase extraction & None & RPLC & MS/MS & $0.05-0.43 \mathrm{ng} / \mathrm{g}$ & $92-104 \%$ & [51] \\
\hline 18 PFASs & Human urine and serum & Solid phase extraction & None & RPLC & MS/MS & $0.1 \mu \mathrm{g} / \mathrm{L}$ & 94-104\% & [52] \\
\hline 21 PFASs & Human serum & Solid phase extraction & None & RPLC & MS/MS & $0.008-0.19 \mu \mathrm{g} / \mathrm{L}$ & $85-114 \%$ & [53] \\
\hline 6 PFASs & Human serum & Deproteinization & MASH & RPLC & MS/MS & $0.07-0.42 \mu \mathrm{g} / \mathrm{L}$ & $96-100 \%$ & [55] \\
\hline 11 PFASs & Human blood & Solvent extraction & None & RPLC & MS/MS & $0.06-0.14 \mu \mathrm{g} / \mathrm{L}$ & $67-112 \%$ & [56] \\
\hline 20 PFASs & Human plasma, BCS & Centrifugation & None & RPLC & MS/MS & $0.024-0.096 \mu \mathrm{g} / \mathrm{L}(\mathrm{LOQ})$ & $83-103 \%$ & [57] \\
\hline
\end{tabular}

PFASs: polyfluoroalkyl substances, MASH: 10-methyl-acridone-2-sulfonohydrazide.

Table 5. Analytical methods for $\alpha$-keto acids and 2-hydroxyglutaric acid (2-HG) in biological samples.

\begin{tabular}{|c|c|c|c|c|c|c|c|c|}
\hline Target Compounds & Biological Sample & Sample Treatment & Derivatization Reagent & Separation Mode & Detection Method & LOD & Recovery & Ref. \\
\hline $4 \alpha$-Keto acids & Human serum & Centrifugation & OPD & RPLC & FL: $350 / 410 \mathrm{~nm}$ & $1 \mu \mathrm{M}$ & $86-109 \%$ & [58] \\
\hline $7 \alpha$-Keto acids & Human neutrophil & Centrifugation & OPD & RPLC & FL: $360 / 415 \mathrm{~nm}$ & $0.035-0.125 \mu \mathrm{M}$ & $79-108 \%$ & [59] \\
\hline $3 \alpha$-Keto acids & Human CML cell & Gel extraction & OPD & RPLC & FL: $360 / 415 \mathrm{~nm}$ & $18-40 \mathrm{nM}$ & $84-96 \%$ & [60] \\
\hline $6 \alpha$-Keto acids & Human CML cell & Centrifugation & DMB & RPLC & FL: $367 / 446 \mathrm{~nm}$ & $1.3-5.4 \mathrm{nM}$ & $86-118 \%$ & [61] \\
\hline $3 \alpha$-Keto acids & Mouse tissue & Acid extraction & OPD & RPLC & MS & $5 \mathrm{nM}$ & $76-95 \%$ & [62] \\
\hline $10 \alpha$-Keto acids & Rat plasma & Centrifugation & O-PFBO & RPLC & MS/MS & $0.01-0.25 \mu \mathrm{M}$ & $96-109 \%$ & [63] \\
\hline $3 \alpha$-Keto acids & Human plasma & Centrifugation & None & RPLC & MS/MS & $0.04 \mu \mathrm{g} / \mathrm{mL}$ & $81-98 \%$ & [64] \\
\hline (R)-2-HG & Human serum & Solid phase extraction & DATAN & RPLC & MS/MS & $0.060 \mu \mathrm{M}$ & $31-32 \%$ & [65] \\
\hline (R)-2-HG & Human urine, cancer tissues & Solvent extraction & TSPC & RPLC & MS/MS & $1.2 \mathrm{fmol}$ & $88-109 \%$ & [66] \\
\hline
\end{tabular}

OPD: o-phenylenediamine, DMB: 1,2-diamino-4,5-methylenedioxybenzene, O-PFBO: O-(2,3,4,5,6-pentafluorobenzyl)oxime, DATAN: (+)-o,o'-diacetyl-L-tartaric anhydride, TSPC:

$\mathrm{N}$-( $p$-toluenesulfonyl)-L-phenylalanyl chloride.

Table 6. Analytical methods for 2-aminothiazoline-4-carboxylic acid (ATCA), 2-methylthiazolidine-4-carboxylic acid (MTCA), and 2-thiothiazolidine-4-carboxylic acid (TTCA) in biological samples.

\begin{tabular}{|c|c|c|c|c|c|c|c|c|}
\hline Target Compounds & Biological Sample & Sample Treatment & Derivatization Reagent & Separation Mode & Detection Method & LOD & Recovery & Ref. \\
\hline ATCA & Rat plasma and organ & Solid phase extraction & None & RPLC & MS/MS & - & - & [67] \\
\hline ATCA & Human urine & MISBSE & None & RPLC & MS/MS & $5 \mu \mathrm{g} / \mathrm{L}$ & - & [68] \\
\hline ATCA & Rat plasma & Solid phase extraction & None & RPLC & MS/MS & $12 \mu \mathrm{g} / \mathrm{L}$ & - & [69] \\
\hline ATCA & Human postmortem blood & Solid phase extraction & None & HILIC & MS/MS & $2.5 \mu \mathrm{g} / \mathrm{L}$ & $81-89 \%$ & [70] \\
\hline ATCA & Human postmortem blood & Solid phase extraction & None & HILIC & MS/MS & $9 \mu \mathrm{g} / \mathrm{L}(\mathrm{LOQ})$ & $88-96 \%$ & [71] \\
\hline ATCA & Human postmortem blood & Liquid-liquid extraction & None & HILIC & MS/MS & $0.43 \mu \mathrm{g} / \mathrm{L}$ & $86-101 \%$ & [72] \\
\hline MTCA & Human blood and urine & Centrifugation & Acetic anhydride & RPLC & MS/MS & $0.1 \mathrm{mg} / \mathrm{L}$ & - & [73] \\
\hline TTCA & Urine & Acid extraction & None & RPLC & UV: $271 \mathrm{~nm}$ & $35 \mu \mathrm{g} / \mathrm{L}$ & $78-87 \%$ & [74] \\
\hline
\end{tabular}


Table 7. Analytical methods for other carboxylic acids in biological samples.

\begin{tabular}{|c|c|c|c|c|c|c|c|c|}
\hline Target Compounds & Biological Sample & Sample Treatment & Derivatization Reagent & $\begin{array}{c}\text { Separation } \\
\text { Mode }\end{array}$ & $\begin{array}{l}\text { Detection } \\
\text { Method }\end{array}$ & LOD & Recovery & Ref. \\
\hline 7 Bile acids & Human saliva & SPE and solvent extraction & 2-Picolylamine & RPLC & MS/MS & $1.5-5.6 \mathrm{fmol}$ & - & [75] \\
\hline 3 Bile acids, 8 fatty acids & Human plasma and saliva & Solid phase extraction & APBQ & RPLC & MS/MS & $0.19-0.51 \mathrm{fmol}$ & - & [76] \\
\hline 7 Bile acids, 9 fatty acids & Human serum & Solvent extraction & DBCETS & RPLC & FL: $300 / 395 \mathrm{~nm}$ & $0.28-0.70 \mathrm{ng} / \mathrm{mL}$ & $92-102 \%$ & [77] \\
\hline 4 Bile acids & C. bovis & Centrifugation & 2-bromo-4'-nitroacetophenone & RPLC & UV: $263 \mathrm{~nm}$ & $0.25-0.31 \mathrm{ng}$ & $94-99 \%$ & [78] \\
\hline \multirow[t]{2}{*}{7 Bile acids } & Human feces & Solid phase extraction & Phenacyl bromide & RPLC & UV: $254 \mathrm{~nm}$ & $1.22-1.46 \mathrm{pmol}$ & $72-102 \%$ & [79] \\
\hline & Human feces & Solid phase extraction & None & PRLC & MS/MS & - & - & [79] \\
\hline $\begin{array}{l}\text { Dihydroxyoxocholestenoic } \\
\text { acids }\end{array}$ & Human CSF and plasma & Solid phase extraction & Isotope-labeled Girard's P Reagent & RPLC & MS & $0.02-0.05 \mathrm{ng} / \mathrm{mL}$ & - & [80] \\
\hline 7 THGC glucuronides & Human urine & Centrifugation & Isotope-labeled DAPPZ & RPLC & MS/MS & $\begin{array}{c}0.008-0.16 \mu \mathrm{g} / \mathrm{mL} \\
\text { (LOQ) }\end{array}$ & - & [81] \\
\hline Orotic acid & Urine & Dilution & None & RPLC & MS/MS & $0.15 \mu \mathrm{M}$ & - & [82] \\
\hline Metabolome & Human urine & Centrifugation & Isotope-labeled DmPABr & RPLC & MS & - & - & [83] \\
\hline Metabolome & Human urine & Centrifugation & Isotope-labeled dansylhydrazine & RPLC & MS & - & - & [84] \\
\hline
\end{tabular}

APBQ: 1-(3-aminopropyl)-3-bromoquinolinium bromide, DBCETS: 2-(7H-dibenzo[a,g]carbazol-7-yl)ethyl 4-methylbenzenesulfonate, DAPPZ: 1-[(4-dimethylaminophenyl)-carbonyl] piperazine, DmPABr: dimethylaminophenacyl bromide. 


\section{Analytical Methods for Carboxylic Acids in Biological Samples}

\subsection{Fatty Acids}

\subsubsection{Analysis of Fatty Acids}

Fatty acids consisting of hydrophobic carbon chains and hydrophilic carboxylic acids are classified into three types depending on the saturation level of the carbon chain moiety (saturated, monounsaturated, and polyunsaturated). A number of fatty acids play critical roles in the body. For example, docosahexaenoic acid (DHA) and eicosapentanoic acid (EPA) (Figure 1), both of which are omega-3 polyunsaturated fatty acids, are not only effective for lowering blood pressure, but are essential for maintaining brain function [85]. Furthermore, fatty acids are related to certain human diseases, such as arteriosclerosis and ischemic heart disease [86,87]. Hence, numerous analytical methods have been developed for fatty acids to elucidate pathological conditions, disease mechanisms, and aid in diagnosis.
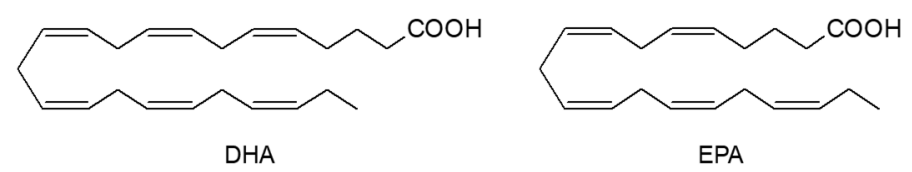

Figure 1. Chemical structures of docosahexaenoic acid (DHA) and eicosapentanoic acid (EPA).

Because some fatty acids are unstable at higher temperatures, LC is generally implemented for analysis instead of GC. In addition, physical properties, such as polarity and molecular weight, vary among fatty acids depending on chain length, necessitating optimization according to target compound properties. LC methods for fatty acids in biological samples are classified based on the detection methods described below.

\subsubsection{Fluorescence Detection}

Fluorescence combined with HPLC is a commonly utilized technique for fatty acids detection, having the advantage of high sensitivity. However, the majority of fatty acids are not fluorescent, necessitating derivatization.

Du et al. designed 6-oxy-(acetylpiperazine)fluorescein (APF), comprised of a fluorescein fluorophore and a piperazine reactive moiety, for carboxylic acid labeling. As shown in Figure 2, seven fatty acids (lauric, myristic, arachidonic, linoleic, palmitic, oleic, and stearic acid) were determined in human serum [7]. APF has the advantages of a relatively straightforward derivatization procedure, high stability, and sensitivity, wherein LODs of 0.1-6.4 $\mathrm{nM}$ are attainable.

2-(2-Naphoxy)ethyl-2-(piperidino)ethanesulfonate (NOEPES) was developed for the quantification of docosaoic (C22), tetracosanic (C24), and hexacosanic (C26) acids [8]. NOEPES is readily removable following derivatization to water-soluble ammonium species, which enables minimal interference when separated by HPLC. The method has been applied to human plasma, and the average levels of C22, C24, and C26 acids were determined to be 566, 398, and $93 \mathrm{nM}$, respectively.

Other methods have been developed employing 9-(2-hydroxyethyl)-carbazole (HEC) as the derivatization reagent $[9,10]$. After addition of 1-ethyl-3-(3-dimethylaminopropyl)-carbodiimide (EDC) and 4-dimethylaminopyridine (DMAP) as condensation reagents, derivatization was performed at $60{ }^{\circ} \mathrm{C}$ for $30 \mathrm{~min}$. The use of $N, N^{\prime}$-carbonyldiimidazole (CDI) instead of EDC improved LODs to 38-57 fmol for C14-C20 fatty acids and even lower for $<\mathrm{C} 14$ fatty acids.

4- $N, N$-Dimethylaminosulfonyl-7- $N$-(2-aminoethyl)amino-2,1,3-benzoxadiazole (DBD-ED) derivatization was reported by Nishikiori et al. [11]. The LODs were in the range of 2.29-4.75 fmol for free fatty acids, and it was applied to measure fatty acid contents in human serum with acid extraction. Recently, DBD-ED was used for the analysis of EPA and DHA in human serum [12]. The DBD-ED 
approach is attractive in terms of sensitivity, but it requires a relatively long reaction time (120 $\mathrm{min})$ compared to other derivatization reagents.

Nithipatikom et al. developed a microbore column LC method using 2-(2,3-naphthalimino)ethyl trifluoromethanesulfonate (NT), for the quantification of endogenous epoxyeicosatrienoic acids from endothelial cells at quantities as low as $2 \mathrm{pg}$ [13].

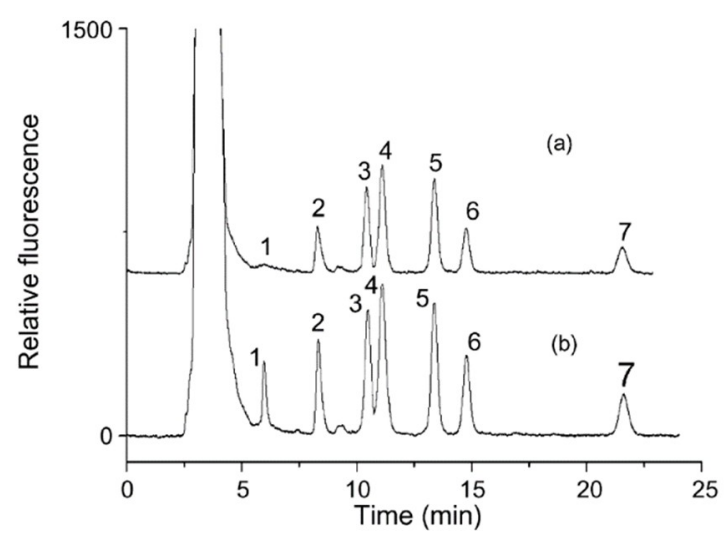

Figure 2. Chromatograms of seven 6-oxy-(acetylpiperazine)fluorescein (APF)-derivatized fatty acids in (a) healthy human serum and (b) sample containing $0.2 \mu \mathrm{M}$ fatty acid standards. Peaks: 1 , lauric acid; 2, myristic acid, 3, arachidonic acid; 4, linoleic acid; 5, palmitic acid; 6, oleic acid; 7, stearic acid. [7]-Reproduced with the permission of Elsevier.

\subsubsection{Mass Spectrometry}

Mass spectrometry is another common detection method for fatty acids. For ESI-MS detection of fatty acids, the negative mode is often practiced with negatively charged fatty acids. However, in general, the negative mode is less sensitive than the positive.

Bollinger et al. developed a method for fatty acid detection by ESI-MS in the positive mode, using $\mathrm{N}$-(4-aminomethylphenyl)pyridinium (AMPP) as a derivatization reagent and accomplished a 64,000 -fold increase in sensitivity compared with that of nonderivatized fatty acids [14,15]. Aminoxy tandem mass tags (aminoxyTMTs) have likewise been used for positive mode detection [16]. This method was applied for the quantification of palmitic acid (C16:0) and docosapentaenoic acid (C22:5) in breast cancer cells. In both minimally and highly invasive cancer cells, levels of C22:5 are markedly higher compared to those in benign breast cells. Several benzofurazan derivatization reagents have been developed for positive ESI-MS detection of fatty acids in rat plasma $[17,18]$. LODs were in the range of $6.5-150 \mathrm{fmol}$.

2-Fluoro-1,3-dimethyl-pyridinium (FDMP) is utilized for converting fatty acids to choline derivatives, which remains permanently ionized in both acidic and basic mobile phases, as shown in Figure 3. The LOD for palmitic acid was $50 \mathrm{ng} / \mathrm{mL}$ in hydrophilic interaction chromatography (HILIC)-ESI-MS [19].

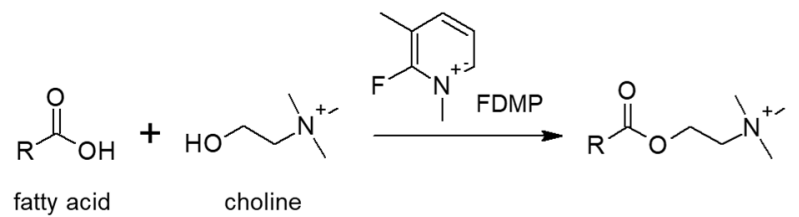

Figure 3. Reaction scheme of fatty acids labeling with choline facilitated by 2-fluoro-1,3-dimethylpyridinium (FDMP).

Chen et al. employed dansylhydrazine to label free fatty acids and acylcarnitines resulting in MS detection of 25 fatty acids and 13 acylcarnitines in human plasma within 12 min (Figure 4a) [20]. 
The derivatization method based on deuterated 2,4-dimethoxy-6-piperazin-1-yl pyrimidine (DMPP) has the advantage of rapid labeling, being executed within $15 \mathrm{sec}$ [21]. 2-Dimethylaminoethylamine (DMED) and $\mathrm{d}_{4}$-DMED derivatization enabled the successfully monitoring of metabolic changes in the unsaturated fatty acid biosynthesis pathway in human serum [22]. Nagy et al. employed a partially miscible solvent and stepwise gradient to achieved rapid analyses of fatty acids without derivatization [23]. Figure $4 \mathrm{~b}$ displays the chromatogram of $\mathrm{C} 16-\mathrm{C} 26$ fatty acids separated via this method within 2 min.
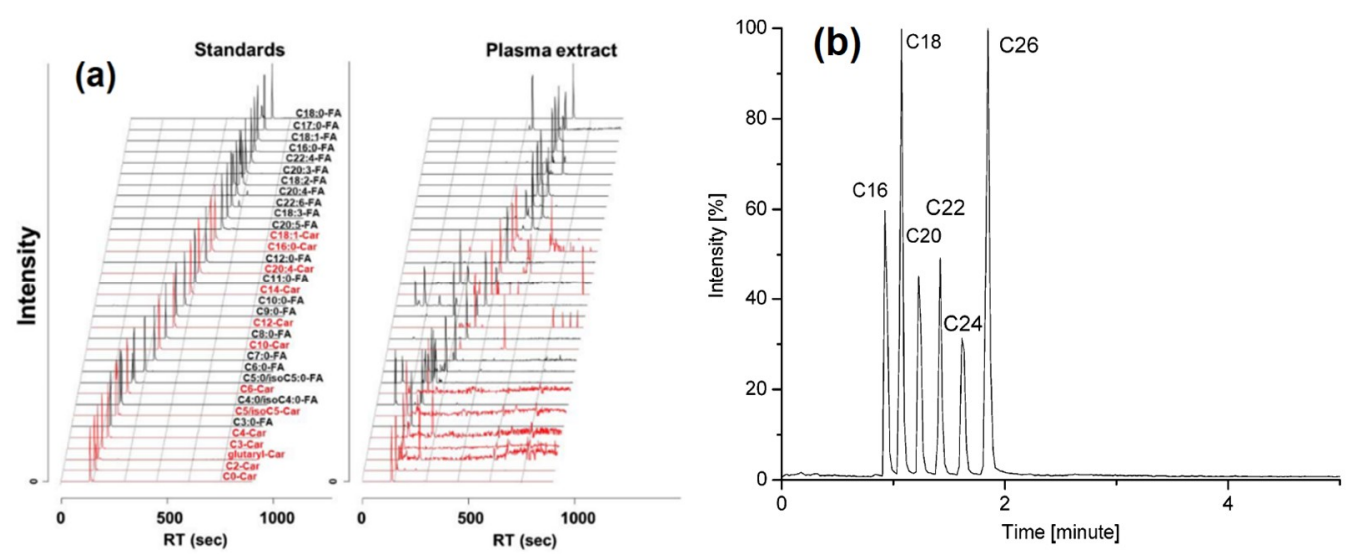

Figure 4. (a) LC-MS/MS chromatogram of derivatized fatty acids and acylcarnitines in the standards sample and plasma extract. [20]—Reproduced with the permission of Springer Nature; (b) LC-MS chromatogram of six non-derivatized fatty acids. [23]—Copyright (2004) American Chemical Society.

\subsubsection{Electrochemical Detection}

Although fluorescence detection has merit in terms of sensitivity, it suffers several disadvantages, including the requirement for sample pretreatment and derivatization. To overcome these drawbacks, HPLC-electrochemical detection methods have been developed [24,25]. Such protocols require merely $20 \mathrm{~min}$ for the complete analysis process of fatty acids without derivatization, wherein separation is achieved within $10 \mathrm{~min}$ (Figure 5). The LOD of $50 \mathrm{pmol}$ renders this technique for application in biological samples, such as serum, plasma, and urine.

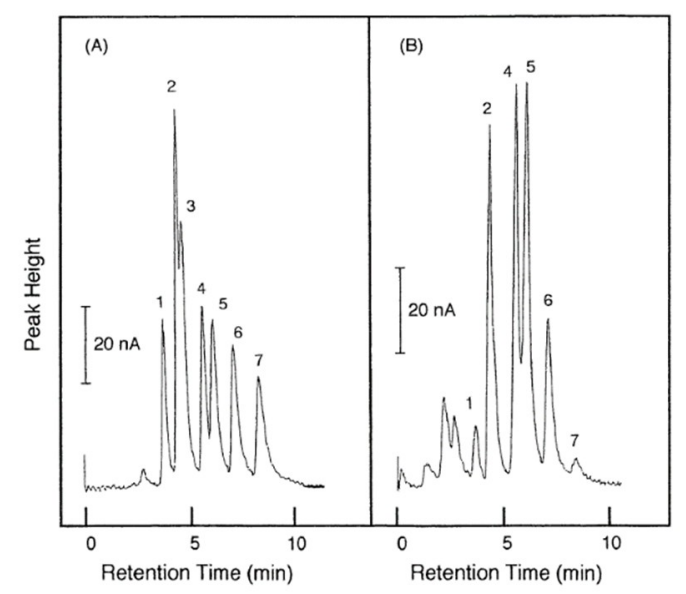

Figure 5. Fatty acid chromatograms of (A) sample with standards and (B) human serum. Peaks: 1, arachidonic acid; 2, palmitoleic and linoleic acids; 3, myristic acid; 4, oleic acid; 5, palmitic acid; 6, margaric acid (IS); 7, stearic acid. [25]—Reproduced with the permission of Elsevier. 


\subsubsection{Electrogenerated Chemiluminescence}

An electrogenerated chemiluminescence (ECL) system has been utilized for the sensitive and selective detection of tertiary amine or diketone moieties. Morita et al. extended the HPLC-ECL technique to myristic acid analysis in human plasma with an LOD of $70 \mathrm{fmol}$ by using $N$-(3-aminopropyl) pyrrolidine (NAPP), which converts fatty acids into tertiary amine derivatives [26].

\subsection{TCA Cycle and Glycolysis-Related Compounds}

Glycolysis and the subsequent TCA cycle are the principal metabolic pathways via which ATP is synthesized by substrate level phosphorylation. Metabolic disorders occurring in these pathways are intrinsically and directly associated with numerous diseases, such as diabetes, kidney disease, and cancer $[88,89]$. The quantification of metabolites is beneficial for clinical diagnoses and quality assurance of organic products. Therefore, simpler, more sensitive and accurate quantification methods have been developed to meet these requirements.

As typified by citric acid, the TCA cycle and glycolysis involve numerous low-molecular-weight high-polarity carboxylic acid metabolites. Moreover, variations in the physical properties of these compounds complicate simultaneous analysis. Therefore, various separation conditions (reversed-phase (RP)LC, ion-pair chromatography, ion-exclusion chromatography, and HILIC), and detection methods (UV, fluorescence, and MS) have been combined to overcome this drawback.

Fumaric acid was quantified with an LC-photodiode array (PDA) to investigate the dynamics of fumaric acid-constitutive drug nanocarriers [27]. Trace levels of maleic acid in healthy rat serum and urine were analyzed with LC-MS/MS [28]. Methylmalonic acid in human plasma was quantified by HILC-MS [29], lactic acid in human urine and saliva with LC-UV and fluorescence detection after fluorescence derivatization (two detection methods were compared) [30], and oxalic acid in mouse urine and hepatocyte samples with ion-exclusion chromatography-MS/MS [31]. These methods were developed for sensitive and selective detection with simple operation.

Simultaneous analysis of numerous carboxylic acid metabolites has been performed by several groups. Kubota et al. quantified six compounds via 4-N,N-dimethylaminosulfonyl-7-piperazino-2,1,3benzoxadiazole (DBD-PZ) derivatization and fluorescence detection [32]. Ion exclusion chromatographyUV detection was implemented for the quantification of 9 and 32 carboxylic acid metabolites, to obtain carboxylic acid profiles of cultured yeast samples [33] and human urine [34]. Figure 6 illustrates the separation of 32 carboxylic acid standards with single-run chromatographic conditions.

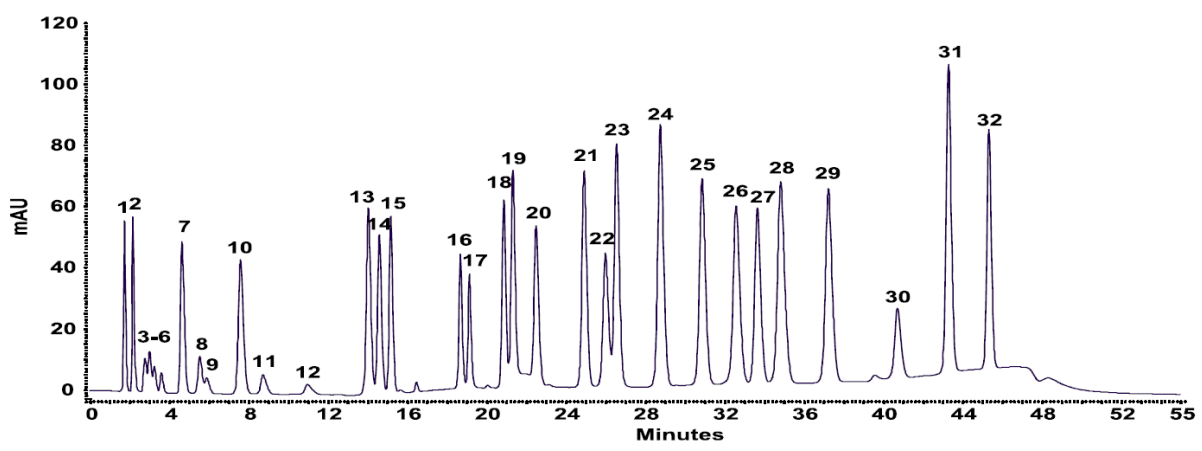

Figure 6. Chromatogram of simultaneous separation of carboxylic acids under single-run chromatographic conditions. Peaks: 1, oxalic; 2, tartaric; 3, malic; 4, malonic; 5, lactic; 6, acetic; 7, maleic; 8 , citric; 9 , succinic; 10 , fumaric; 11 , propionic; 12 , levulinic; 13 , methylsuccinic; 14 , pyromellitic; 15, gallic; 16, protocatechuic; 17,3,5-dihydroxybenzoic; 18, trimellitic; 19, phthalic; 20, 4-hydroxybenzoic; 21, 2,4-dihydroxybenzoic; 22, vanillic; 23 , syringic; 24, 2-methoxybenzoic; 25 , trimesic; 26 , benzoic; 27, ferulic; 28, salicylic; 29, 3-methoxybenzoic; 30, 2-methylbenzoic; 31, cinnamic; 32, 3-methoxycinnamic acid. [34]-Reproduced with the permission of Springer Nature. 
Similarly, comprehensive analyses including that of carboxylic acid metabolites of the TCA cycle and glycolysis have been conducted with various separation and detection methods: 13 compounds via HPLC-fluorescence detection aided by 1-pyrenemethylamine derivatization [35], 30 compounds with HILIC or ion-pair chromatography-MS/MS [36], 59 compounds with ion-pair chromatography-MS [37], and 138 compounds with UHPLC-MS/MS [38]. Nemkov et al. comprehensively analyzed TCA cycle metabolites to elucidate the effects of hypoxia on carboxylic acid metabolism in red blood cells [39].

\subsection{Amino Acid Metabolites}

Amino acid analysis is immensely important, as they are essential structural units of protein. Recent analytical methods for the quantification of amino acids have been summarized in our previous review [90]. These methods contribute to the diagnosis and elucidation of disease mechanisms, such as diabetes, kidney disease, and liver disease. Measurement of amino acid metabolite levels is likewise beneficial for understanding diseases.

Among amino acid metabolites, tryptophan and tyrosine metabolites are most commonly analyzed (Figure 7). Kynurenine and kynurenic acid, which are tryptophan metabolites that are intricately related to diseases such as schizophrenia [91], Parkinson's disease, and Alzheimer's disease [92], have been quantified using HPLC-fluorescence detection. Indole derivatives and glycated tryptophan in rat plasma, mouse plasma, and brain were analyzed with fluorescence detection [40,41], and those in livestock urine and plasma were analyzed with LC-MS to monitor their health [42-44]. Valko-Rokytovska et al. quantified melanin-related carboxylic compounds in human urine by HPLC-UV for the diagnosis of melanoma cancer, and found that homovanilic acid and tryptophan levels increased in the initial clinical stage of the disease [45]. Catechol-bearing carboxylic acids were separated by ion exchange chromatography, followed by derivatization with ethylenediamine and fluorescence detection [46]. The concentrations of dopamine metabolites, 3,4-dihydroxyphenylacetic and homovanillic acid were determined as 131 and $404 \mathrm{nM}$ in rat kidney samples, and the LODs per injection were 50 and $100 \mathrm{fmol}$, respectively. Huang et al. quantified nicotinic acid in human plasma by LC-MS/MS to examine its side effects, as it is administered as a potent vitamin at milligram doses [47].<smiles>Nc1ccccc1C(=O)CC(N)C(=O)O</smiles>

kynurenine<smiles>O=C(O)c1cc(O)c2ccccc2n1</smiles>

kynurenic acid<smiles>COc1cc(CC(=O)O)ccc1O</smiles>

homovanilic acid<smiles>O=C(O)Cc1ccc(O)c(O)c1</smiles>

3,4-dihydroxyphenylacetic acid<smiles>O=C(O)c1cccnc1</smiles>

nicotinic acid<smiles>O=C(O)CCCC(=O)O</smiles>

glutaric acid<smiles>O=C(O)CC(O)CC(=O)O</smiles>

3-hydroxyglutaric acid

Figure 7. Chemical structures of amino acid metabolites.

Glutaric and 3-hydroxyglutaric acid were analyzed in urine samples by UHPLC-MS/MS via derivatization with 4-[2-(N,N-dimethylamino)ethylaminosulfonyl]-7-(2-aminoethylamino)-2,1,3benzoxadiazole (DAABD-AE), capable of selectively reacting with dicarboxylic compounds [48]. Levels of both compounds increased significantly in glutaric acidemia type I patients, and it was concluded that glutaric acid analysis was beneficial for the precise diagnosis of the disease.

Comprehensive analysis of amino acids, N-acetylated amino acids, and other organic acids in human urine and human pancreatic cancer cells was conducted via derivatization with dimethylaminophenacyl bromide (DmPABr) for MS/MS [49]. DmPABr labels carboxylic acids, thiols, and amines simultaneously, resulting in the appearance of several labelling patterns (Figure 8). 
The LODs of a total of 64 compounds ranged between 0.11 and $2192 \mathrm{nM}$, and, importantly, it was below $10 \mathrm{nM}$ for approximately half of them.

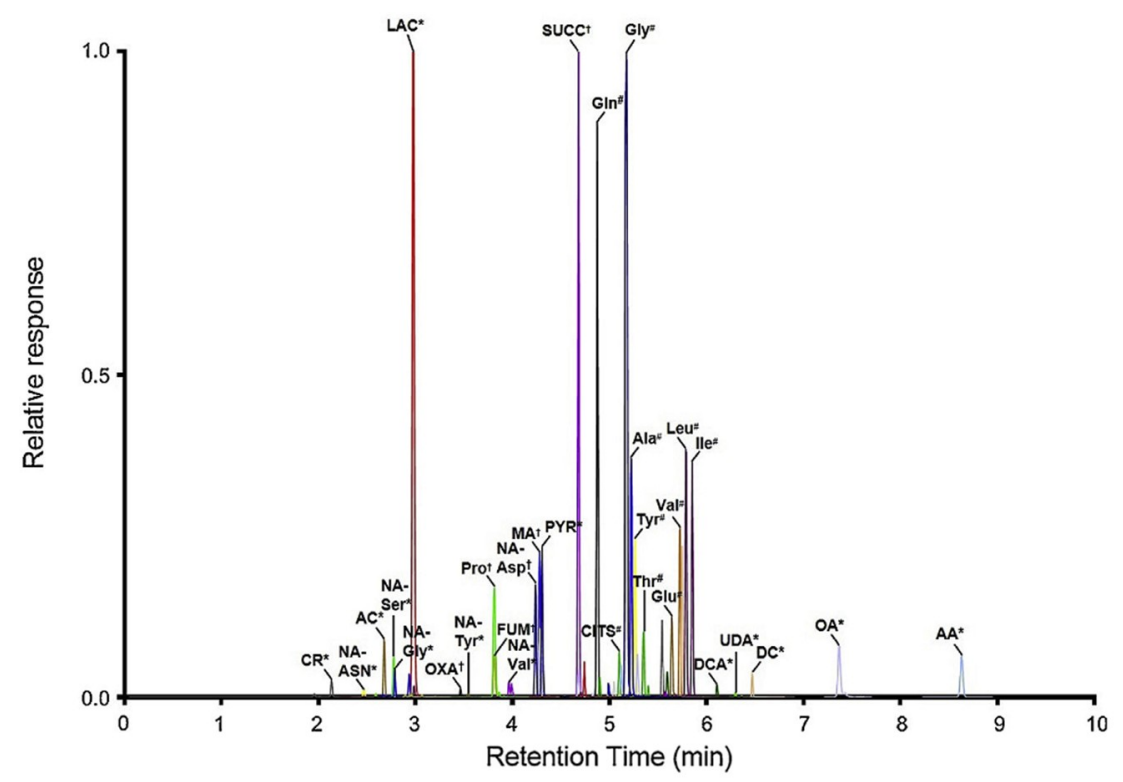

Figure 8. LC-MS/MS chromatogram of 64 metabolites after dimethylaminophenacyl bromide (DmPABr) derivatization in SUIT-2 cells. DmPA labeling patterns are also included ${ }^{*}=$ labeled once; $\dagger=$ labeled twice; \# = labeled thrice). [49]—Reproduced with the permission of Elsevier.

\subsection{Perfluorinated Carboxylic Acids}

Perfluorinated carboxylic acids (PFCAs) are synthetic substances used in numerous products such as food packaging paper and impregnation sprays. They are widespread organic pollutants and have been reported to accumulate in the human body because they are resistant to metabolism [93]. Although critical adverse effects of PFCAs on human health have not been reported, evaluation of their accumulation in the body is critical for further investigation of PFCA effects.

Several sample pretreatments, such as solid-phase extraction (SPE), liquid-liquid extraction (LLE), or solvent precipitation can be performed, the most common method being SPE. Maestri et al. analyzed perfluorooctanoic acid using a C18 disposable SPE cartridge [50]. Oasis WAX cartridges, wherein extraction is conducted in a mixed mode of RP and weak anion exchange, have likewise been used [51,52]. Prior to SPE operation, a mixture of $\mathrm{HCl}$ and $\mathrm{HNO}_{3}$ was added to eliminate the matrix, in the case of bivalve samples, leading to improved recoveries (92-104\%) and selectivity. The developed method was applied to shell and soft tissues, and no significant relationship was found between PFCA levels in shell and soft tissues.

Gao et al. established an online SPE-LC-MS/MS method for 21 per- and polyfluoroalkyl substances including 13 PFCAs, featuring a rapid processing time (20 min per sample) and favorable peak shapes [53]. Perfluorobutanoic and perfluorooctanoic acid concentrations were found to be significantly higher in the serum of employees of fluorochemical manufacturing plants than those in the general population. Micro-solid phase extraction ( $\mu$-SPE) can determine trace levels of PFCAs in human plasma [54]. Zhang et al. precipitated proteins using acetonitrile and derivatized PFCAs with 10-methyl-acridone-2-sulfonohydrazide (MASH) to eliminate the matrix effect [55]. Chromatograms of MASH-derivatized PFCAs in serum samples are shown in Figure 9. 


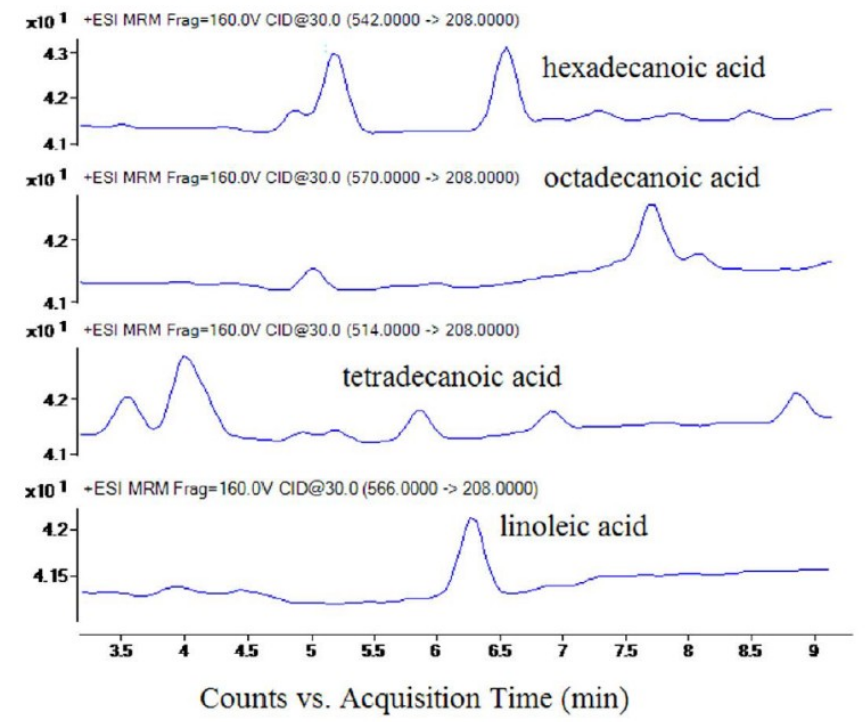

Figure 9. LC-MS/MS chromatograms of 10-methyl-acridone-2-sulfonohydrazide (MASH)-derivatized PFCAs in serum samples. [55]—Reproduced with the permission of Elsevier.

\section{5. $\alpha$-Keto Acids and Their Metabolites}

\subsection{1. $\alpha$-Keto Acids}

$\alpha$-Keto acids are synthesized from $\alpha$-amino acids via transamination. Some biological $\alpha$-keto acids ( $\alpha$-ketoglutaric acid, $\alpha$-ketoisovaleric acid, $\alpha$-ketoisocaproic acid, and $\alpha$-keto- $\beta$-methylvaleric acid, Figure 10) are assembled from $\alpha$-amino acids by branched-chain amino acid transferase (BCAT), and others are likewise found in amino acid metabolic pathways. We found that BCAT1 plays a significant role in the development of chronic myeloid leukemia [94]. In addition, disorders of $\alpha$-keto acid levels in biological fluids are related to diseases such as diabetes mellitus, maple syrup urine disease, and ketoacidosis $[95,96]$. Therefore, the analysis of $\alpha$-keto acids is attracting increasing interest.<smiles>O=C(O)CCC(=O)C(=O)O</smiles>

a-ketoglutaric acid<smiles>CC(C)C(=O)C(=O)O</smiles>

a-ketoisovaleric acid<smiles>CC(C)CC(=O)C(=O)O</smiles>

a-ketoisocaproic acid<smiles>CCC(C)C(=O)C(=O)O</smiles>

$\alpha$-keto- $\beta$-methylvaleric acid

Figure 10. Chemical structures of $\alpha$-keto acids.

As $\alpha$-keto acids are not fluorescent, their detection was accomplished with fluorescence detection after derivatization. Derivatization reagents such as $o$-phenylenediamine (OPD) and 1,2-diamino-4,5-methylenedioxybenzene (DMB) can execute an $\alpha$-keto-acid-selective reaction through the recognition of two conjugated carbonyl groups.

Quantification entailing OPD derivatization and fluorescence detection has been reported by several groups, wherein LODs were between $18 \mathrm{nM}$ and $1 \mu \mathrm{M}$ [58-60]. DMB was developed to improve the sensitivity of fluorescence detection, and has a structure similar to that of OPD. As shown in Figure 11, we quantified $\alpha$-keto acids in chronic myeloid leukemia cells to investigate the role of BCAT1 [61]. The concentrations of six $\alpha$-keto acids were between 1.55 and 316 pmol per 106 cells and LODs were within 1.3 and $5.4 \mathrm{nM}$, being three-fold higher than that of OPD. 


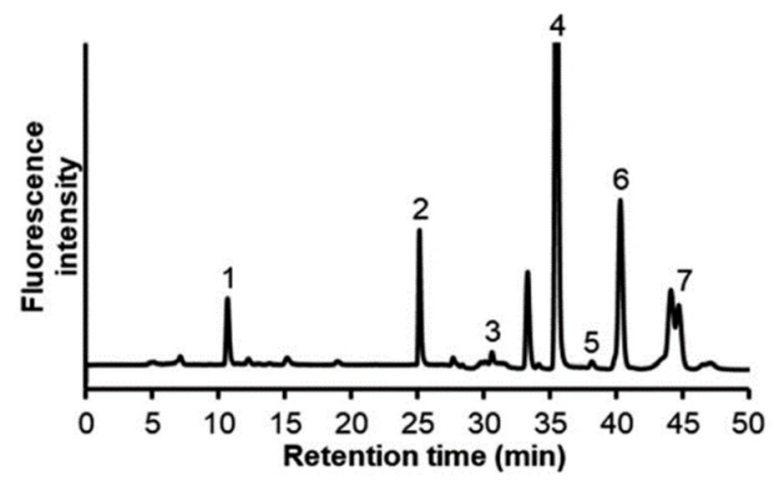

Figure 11. Chromatogram of 1,2-diamino-4,5-methylenedioxybenzene (DMB)- $\alpha$-keto acids in K562 cell sample. Peaks: 1, DMB- $\alpha$-ketoglutaric acid; 2, DMB-pyruvic acid; 3, DMB- $\alpha$-ketobutyric acid, 4 , DMB- $\alpha$-ketvaleric acid; 5, DMB- $\alpha$-ketoisovaleric acid; 6 , DMB- $\alpha$-ketoisocaproic acid; 7, DMB- $\alpha$-keto- $\beta$ methylvaleric acid. [61]—Reproduced with the permission of The Royal Society of Chemistry.

OPD derivatization was also employed for MS, resulting in a lowered LOD of $5 \mathrm{nM}$. Tissue samples from PP2Cm knockout mice had 22-86 times higher branched-chain $\alpha$-keto acids than wild-type mice [62]. Ten $\alpha$-keto acids were analyzed with $O$-(2,3,4,5,6-pentafluorobenzyl)oxime (O-PFBO) derivatization and MS/MS. The method was applicable to the comprehensive analysis of $\alpha$-keto acids in rat plasma [63]. Li et al. analyzed branched-chain $\alpha$-keto acids and $\alpha$-amino acids simultaneously by MS/MS without derivatization and found significant differences in the concentrations of six compounds in patients with cerebral infarction and those of healthy individuals [64].

\subsubsection{2-Hydroxyglutaric Acid}

2-Hydroxyglutaric acid (2-HG, Figure 12) is an oncometabolite produced from $\alpha$-ketoglutaric acid. Because 2-HG is chiral and only $(R)-2-\mathrm{HG}$ is a cancer metabolite, it is necessary to separate the enantiomeric isomers. One of the strategies for separating enantiomeric isomers is the chiral derivatization method. (+)-O, $\mathrm{O}^{\prime}$-Diacetyl-L-tartaric anhydride (DATAN) [65] and $\mathrm{N}$-( $p$-toluenesulfonyl)L-phenylalanyl chloride (TSPC) [66] are two reagents developed for this purpose. Both reagents have been used for RPLC-MS/MS analysis. Whereas TSPC was superior to DATAN in sensitivity (LOD of (R)-2-HG was $1.2 \mathrm{fmol}$ with TSPC and 115 fmol with DATAN), DATAN enabled faster separation than TSPC (23 min for TSPC, 6 min for DATAN). Figure 13 illustrates the separation of enantiomers by TSPC derivatization [66]. It was revealed that levels of both (R)- and (S)-2-HG in human urine were comparable among patients with type 2 diabetes mellitus, lung cancer, colorectal cancer, and nasopharyngeal carcinoma. On the other hand, both isomers of 2-HG in human tissue were significantly increased.<smiles>O=C(O)CC[C@H](O)C(=O)O</smiles>

(R)-2-HG<smiles>O=C(O)CC[C@H](O)C(=O)O</smiles>

(S)-2-HG

Figure 12. Chemical structures of (R)- and (S)-2-hydroxyglutaric acid (2-HG). 


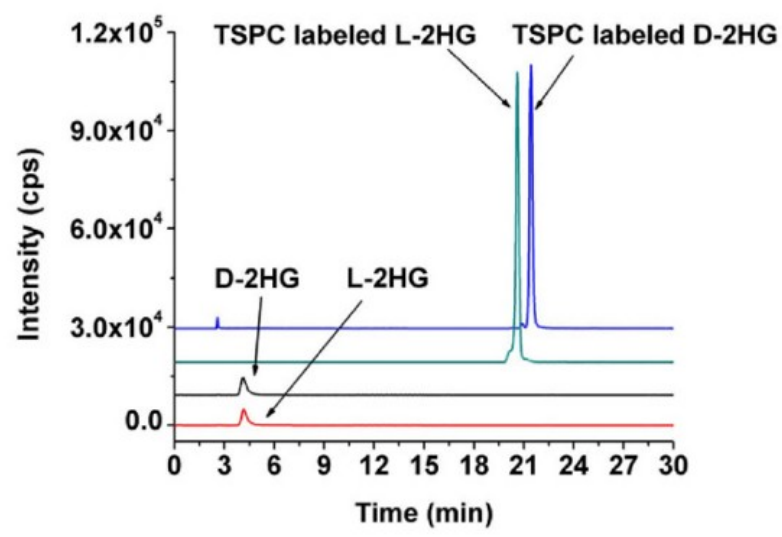

Figure 13. LC-MS/MS chromatograms of non-labeled and $N$-(p-toluenesulfonyl)-L-phenylalanyl chloride (TSPC)-labeled ( $R$ )- and (S)-2-HG (D and L, respectively). [66].

\subsection{Carboxylic Acids Containing a Thiazole Ring}

2-Aminothiazoline-4-carboxylic acid (ATCA, Figure 14) is a cyanide metabolite and is expected to be a biomarker of cyanide-related diseases due to its thermal and long-term stability in biological samples. In forensic cases, whole blood is the preferred biological sample, and it is necessary to purify ATCA from blood because of its high viscosity and complex composition. Purification methods using cation-exchange SPE [67] and molecularly imprinted polymer-stir bar sorptive extraction (MISBSE) [68] have been proposed, to be followed by LC-MS/MS. SPE offered adequate precision of $5.9 \%$ RSD, but interferences derived from whole blood were detected near the ATCA peak. On the other hand, MIP-SBSE produced a single peak derived from ATCA, but the capacity was insufficient and the method suffered from low recoveries [69]. Lulinski et al. synthesized a novel imprinted material in a dispersive SPE, providing a rapid (35 min for extraction) and low-cost clean-up technique [70]. After investigation of the surface morphology, interferences were significantly reduced. A robust SPE was developed for hydrophilic interactions, allowing for a high accuracy of $96 \%$ [71]. Furthermore, it is environmentally benign and entails a simple procedure. Analysis of human postmortem blood from individuals who died due to oral cyanide exposure established that ATCA is an adequate cyanide exposure marker.<smiles>N=c1[nH]c(C(=O)O)cs1</smiles>

ATCA<smiles>CC1NC(C(=O)O)CS1</smiles>

MTCA<smiles>O=C(O)C1CSC(=S)N1</smiles>

TTCA

Figure 14. Chemical structures of 2-aminothiazoline-4-carboxylic acid (ATCA), 2-methylthiazolidine-4carboxylic acid (MTCA), and 2-thiothiazolidine-4-carboxylic acid (TTCA).

Although LLE offered good accuracy and sensitivity with an LOD of $0.43 \mathrm{ng} / \mathrm{mL}$, derivatization of interference compounds (secondary amino acids) was required to remove interference peaks [72]. It was applied to human blood and revealed that ATCA concentrations in blood from a cyanide-poisoned person were approximately four-fold higher than those from non-poisoned persons.

2-Methylthiazolidine-4-carboxylic acid (MTCA, Figure 14) is produced by the reaction of acetaldehyde and cysteine, and it is a biomarker for recent alcohol consumption. MTCA has been derivatized with acetic anhydride and then analyzed by reversed-phase LC-ESI-MS [73]. Free MTCA is unstable under physiological conditions as it is readily hydrolyzed. Hence, the quantification of MTCA was enabled by $\mathrm{N}$-acetylation. 
2-Thiothiazolidine-4-carboxylic acid (TTCA, Figure 14) is a urinary metabolite derived from carbon disulfide. Methyl t-butyl ether and diethyl ether have been utilized as extraction solvents for TTCA, the former being superior in terms of TTCA recovery (78-87\% against $67-80 \%$ ) as well as storage stability as it produces less peroxides during storage [74]. After extraction, TTCA was analyzed by reversed-phase LC-UV.

\subsection{Miscellaneous}

Other biological carboxylic acids not discussed in the above sections are described here. The detection method was optimized for the physical properties of each compound.

Bile acids and their metabolites have been analyzed using several different derivatization reagents. Higashi et al. developed an analytical method employing 2-picolylamine derivatization and MS/MS detection and monitored these compounds in human saliva [75]. Sensitivity in MS/MS was improved by approximately ten-fold by 1-(3-aminopropyl)-3-bromoquinolinium bromide (APBQ) derivatization [76]. Concentrations of deoxycholic acid and chenodeoxycholic acid (Figure 15) in human plasma were 91 and $445 \mathrm{nM}$, respectively. 2-(7H-Dibenzo[a,g]carbazol-7-yl)ethyl 4-methylbenzenesulfonate (DBCETS) derivatization was also performed for fluorescence detection to determine bile acid concentrations in human serum [77]. Derivatization with 2-bromo-4'-nitroacetophenone and phenacyl bromide was also used for UV detection [78,79].
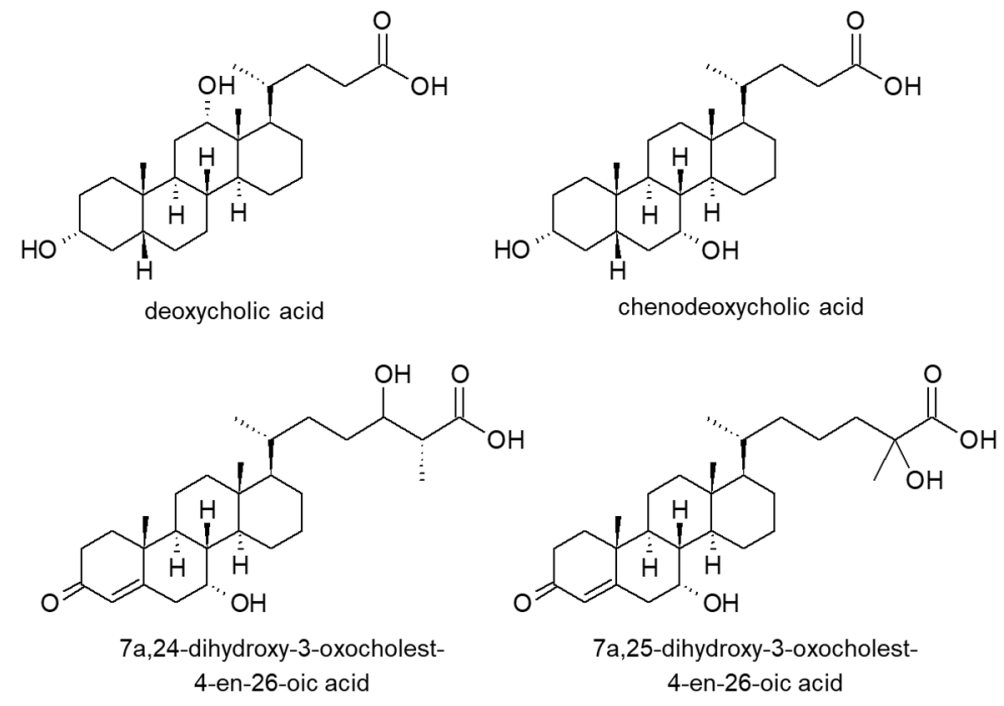

Figure 15. Chemical structures of bile acids and their metabolites.

As intermediates of bile acid biosynthesis, dihydroxyoxocholestenoic acids were quantified using LC-MS [80]. It was found that concentrations of $7 \alpha, 24$ - and 7 $\alpha, 25$-dihydroxy-3-oxocholest-4-en-26-oic acids (Figure 15) in cerebrospinal fluid were reduced in patients with hereditary spastic paraplegia type 5 . Tetrahydroglucocorticoid glucuronides in human urine were quantified with 1-[(4-dimethylaminophenyl)carbonyl]piperazine (DAPPZ) to diagnose diseases caused by abnormal cortisol secretion [81].

Orotic acid, which is useful for diagnosing urea cycle disorder or hereditary orotic aciduria, was analyzed by LC-MS/MS. with an LOD of $150 \mathrm{nM}$ [82].

Metabolome analysis is challenging because a variety of carboxylic compounds with a wide range of concentrations in complex biological samples need to be simultaneously detected. Guo et al. implemented isotope-labeled DmPABr derivatization and LC-MS, resulting in the identification of 51 carboxylic compounds in urinary samples [83]. Isotope-labeled dansylhydrazine was also used to identify 81 compounds in the urinary sample [84]. The research was conducted as a demonstration; therefore, further application of the method is expected. 


\section{Conclusions}

In this review, LC methods for the quantification of carboxylic acids in biological samples, such as plasma, serum, and urine, were summarized. In general, a practical analytical method is achieved when several aspects are promoted: high sensitivity, high selectivity, rapid analysis, minimal reagent and equipment requirements, and simple operation. Numerous analytical methods have been developed to improve upon the existing ones.

The most commonly employed detection methods include fluorescence and MS. Fluorescence detection achieves a relatively better detection limit with simple equipment, but required fluorescence derivatization. For MS analysis, various types of compounds could be analyzed simultaneously without derivatization. Derivatization reagents for MS have been used not only for improved separation but also for enhancing sensitivity and selectivity. In addition, short-time analyses have been developed with optimized derivatization reagents and separation conditions.

Practical and efficient analytical methods are continually being developed to meet the requirements of quantifying various compounds in diverse samples. The utilization of these methods is beneficial for elucidating disease mechanisms, and further contributions to disease diagnosis and treatment are anticipated.

Author Contributions: Conceptualization, M.T. writing-original draft preparation, T.F., R.I., T.O., and M.T.; writing-review and editing, T.F. and M.T.; funding acquisition, M.T. All authors have read and agreed to the published version of the manuscript.

Funding: This research was funded by Grant-in-Aid for Scientific Research (C) (17K08234) from the Japan Society for the Promotion of Science (JSPS).

Conflicts of Interest: The authors declare no conflict of interest.

\section{References}

1. Theodoridis, G.A.; Gika, H.G.; Want, E.J.; Wilson, I.D. Liquid chromatography-mass spectrometry based global metabolite profiling: A review. Anal. Chim. Acta 2012, 711, 7-16. [CrossRef] [PubMed]

2. Chen, J.; Wang, W.; Lv, S.; Yin, P.; Zhao, X.; Lu, X.; Zhang, F.; Xu, G. Metabonomics study of liver cancer based on ultra performance liquid chromatography coupled to mass spectrometry with HILIC and RPLC separations. Anal. Chim. Acta 2009, 650, 3-9. [CrossRef] [PubMed]

3. Xu, X.; Roman, J.M.; Issaq, H.J.; Keefer, L.K.; Veenstra, T.D.; Ziegler, R.G. Quantitative Measurement of Endogenous Estrogens and Estrogen Metabolites in Human Serum by Liquid Chromatography-Tandem Mass Spectrometry. Anal. Chem. 2007, 79, 7813-7821. [CrossRef] [PubMed]

4. Tsunoda, M.; Sumida, Y. Liquid Chromatography|Amino Acids. Encycl. Anal. Sci. (3rd ed.) 2019, 6, 1-11.

5. Isokawa, M.; Kanamori, T.; Funatsu, T.; Tsunoda, M. Analytical methods involving separation techniques for determination of low-molecular-weight biothiols in human plasma and blood. J. Chromatogr. B 2014, 964, 103-115. [CrossRef] [PubMed]

6. Tsunoda, M. Recent advances in methods for the analysis of catecholamines and their metabolites. Anal. Bioanal. Chem. 2006, 386, 506-514. [CrossRef]

7. Du, X.-L.; Zhang, H.-S.; Guo, X.-F.; Deng, Y.-H.; Wang, H. 6-Oxy-(acetyl piperazine) fluorescein as a new fluorescent labeling reagent for free fatty acids in serum using high-performance liquid chromatography. J. Chromatogr. A 2017, 1169, 77-85. [CrossRef] [PubMed]

8. Lu, C.-Y.; Wu, H.-L.; Chen, S.-H.; Kou, H.-S. A Fluorimetric Liquid Chromatography for Highly Sensitive Analysis of Very Long Chain Fatty Acids as Naphthoxyethyl Derivatives. Chromatographia 2000, 51, 315-321. [CrossRef]

9. You, J.; Zhang, W.; Jia, X.; Zhang, Y. An Improved Derivatization Method for Sensitive Determination of Fatty Acids by High-Performance Liquid Chromatography Using 9-(2-hydroxylethyl)-Carbazole as Derivatization Reagent with Fluorescence Detection. Chromatographia 2001, 54, 316-322. [CrossRef]

10. You, J.; Zhang, W.; Zhang, Y. Simple derivatization method for sensitive determination of fatty acids with fluorescence detection by high-performance liquid chromatography using 9-(2-hydroxyethyl)-carbazole as derivatization reagent. Anal. Chim. Acta 2001, 436, 163-172. [CrossRef] 
11. Nishikiori, M.; Iizuka, H.; Ichiba, H.; Sadamoto, K.; Fukushima, T. Determination of Free Fatty Acids in Human Serum by HPLC with Fluorescence Detection. J. Chromatogr. Sci. 2015, 53, 537-541. [CrossRef] [PubMed]

12. Onozato, M.; Okanishi, Y.; Akutsu, M.; Okumura, I.; Nemoto, A.; Takano, K.; Sakamoto, T.; Ichiba, H.; Fukushima, T. Alteration in plasma docosahexanoic acid levels following oral administration of ethyl icosapentate to rats. Pract. Lab. Med. 2020, 18, e00143. [CrossRef] [PubMed]

13. Nithipatikom, K.; Pratt, P.F.; Campbell, W.B. Determination of EETs using microbore liquid chromatography with fluorescence detection. Am. J. Physiol. Heart Circ. Physiol. 2000, 279, 857-862. [CrossRef] [PubMed]

14. Bollinger, J.G.; Rohan, G.; Sadilek, M.; Gelb, M.H. LC/ESI-MS/MS detection of FAs by charge reversal derivatization with more than four orders of magnitude improvement in sensitivity. J. Lipid Res. 2013, 54, 3523-3530. [CrossRef]

15. Bollinger, J.G.; Thompson, W.; Lai, Y.; Oslund, R.C.; Hallstrand, T.S.; Sedilek, M.; Turecek, F.; Gelb, M.H. Improved Sensitivity Mass Spectrometric Detection of Eicosanoids by Charge Reversal Derivatization. Anal. Chem. 2010, 82, 6790-6796. [CrossRef]

16. Sun, F.; Choi, A.A.; Wu, R. Systematic Analysis of Fatty Acids in Human Cells with a Multiplexed Isobaric Tag (TMT)-Based Method. J. Proteome Res. 2018, 17, 1606-1614. [CrossRef]

17. Tsukamoto, Y.; Santa, T.; Yoshida, H.; Miyano, H.; Fukushima, T.; Hirayama, K.; Imai, K.; Funatsu, T. Synthesis of the isotope-labeled derivatization reagent for carboxylic acids, 7-( $N, N$-dimethylaminosulfonyl)4-(aminoethyl)piperazino-2,1,3-benzoxadiazole $\left(\mathrm{d}_{6}\right)$ [DBD-PZ- $\mathrm{NH}_{2}(\mathrm{D})$ ], and its application to the quantification and the determination of relative amount of fatty acids in rat plasma samples by high-performance liquid chromatography/mass spectrometry. Biomed. Chromatogr. 2006, 20, 358-364.

18. Tsukamoto, Y.; Santa, T.; Saimaru, H.; Imai, K.; Funatsu, T. Synthesis of benzofurazan derivatization reagents for carboxylic acids and its application to analysis of fatty acids in rat plasma by high-performance liquid chromatography-electrospray ionization mass spectrometry. Biomed. Chromatogr. 2005, 19, 802-808. [CrossRef]

19. Abualhasan, M.N.; Watson, D.G. Tagging Fatty Acids Via Choline Coupling for the Detection of Carboxylic Acid Metabolites in Biological Samples. Curr. Anal. Chem. 2019, 15, 642-647. [CrossRef]

20. Chen, G.-Y.; Zhang, Q. Simultaneous quantification of free fatty acids and acylcarnitines in plasma samples using dansylhydrazine labeling and liquid chromatography-triple quadrupole mass spectrometry. Anal. Bioanal. Chem. 2020, 412, 2841-2849. [CrossRef]

21. Leng, J.; Wang, H.; Zhang, L.; Zhang, J.; Wang, H.; Guo, Y. A highly sensitive isotope-coded derivatization method and its application for the mass spectrometric analysis of analytes containing the carboxyl group. Anal. Chim. Acta 2013, 758, 114-121. [CrossRef] [PubMed]

22. Zhu, Q.-F.; Zhang, Z.; Liu, P.; Zheng, S.-J.; Peng, K.; Deng, Q.-Y.; Zheng, F.; Yuan, B.-F.; Feng, Y.-Q. Analysis of liposoluble carboxylic acids metabolome in human serum by stable isotope labeling coupled with liquid chromatography-mass spectrometry. J. Chromatogr. A 2016, 1460, 100-109. [CrossRef] [PubMed]

23. Nagy, K.; Jakab, A.; Fekete, J.; Vékey, K. An HPLC-MS Approach for Analysis of Very Long Chain Fatty Acids and Other Apolar Compounds on Octadecyl-Silica Phase Using Partly Miscible Solvents. Anal. Chem. 2004, 76, 1935-1941. [CrossRef] [PubMed]

24. Kotani, A.; Kusu, F.; Takamura, K. New electrochemical detection method in high-performance liquid chromatography for determining free fatty acids. Anal. Chim. Acta 2002, 465, 199-206. [CrossRef]

25. Kotani, A.; Fuse, T.; Kusu, F. Determination of Plasma Free Fatty Acids by High-Performance Liquid Chromatography with Electrochemical Detection. Anal. Biochem. 2000, 284, 65-69. [CrossRef]

26. Morita, H.; Konishi, M. Electrogenerated Chemiluminescence Derivatization Reagents for Carboxylic Acids and Amines in High-Performance Liquid Chromatography Using Tris(2,2'-bipyridine)ruthenium(II). Anal. Chem. 2002, 74, 1584-1589. [CrossRef]

27. Baati, T.; Horcajada, P.; Gref, R.; Couvreur, P.; Serre, C. Quantification of fumaric acid in liver, spleen and urine by high-performance liquid chromatography coupled to photodiode-array detection. J. Pharm. Biomed. Anal. 2011, 56, 758-772. [CrossRef]

28. Chen, H.-C.; Wu, C.; Wu, K.-Y. Determination of the maleic acid in rat urine and serum samples by isotope dilution-liquid chromatography-tandem mass spectrometry with on-line solid phase extraction. Talanta 2015, 136, 9-14. [CrossRef] 
29. Lakso, H.; Appelblad, P.; Schneese, J. Quantification of Methylmalonic Acid in Human Plasma with Hydrophilic Interaction Liquid Chromatography Separation and Mass Spectrometric Detection. Clin. Chem. 2008, 54, 2028-2035. [CrossRef]

30. Pellegrini, D.; Onor, M.; Degano, I.; Bramanti, E. Development and validation of a novel derivatization method for the determination of lactate in urine and saliva by liquid chromatography with UV and fluorescence detection. Talanta 2014, 130, 280-287. [CrossRef]

31. Schriewer, A.; Brink, M.; Gianmoena, K.; Cadenas, C.; Hayen, H. Oxalic acid quantification in mouse urine and primary mouse hepatocyte cell culture samples by ion exclusion chromatography-mass spectrometry. J. Chromatogr. B 2017, 1068-1069, 239-244. [CrossRef] [PubMed]

32. Kubota, K.; Fukushima, T.; Yuji, R.; Miyano, H.; Hirayama, K.; Santa, T.; Imai, K. Development of an HPLC-fluorescence determination method for carboxylic acids related to the tricarboxylic acid cycle as a metabolome tool. Biomed. Chromatogr. 2005, 19, 788-795. [CrossRef] [PubMed]

33. Niu, H.; Chen, Y.; Xie, J.; Chen, X.; Bai, J.; Wu, J.; Liu, D.; Ying, H. Ion-Exclusion Chromatography Determination of Organic Acid in Uridine 5'-Monophosphate Fermentation Broth. J. Chromatogr. Sci. 2012, 50, 709-713. [CrossRef] [PubMed]

34. Halko, R.; Hukelová, I. Single-Run Separation and Determination of Aliphatic and Aromatic Carboxylic Acids in Wine and Human Urine Samples by Ion-Exclusion Chromatography. Chromatographia 2014, 77, 1037-1046. [CrossRef]

35. Todoroki, K.; Hashimoto, H.; Machida, K.; Itoyama, M.; Hayama, T.; Yoshida, H.; Nohta, H.; Nakashima, M.; Yamaguchi, M. Fully automated reagent peak-free liquid chromatography fluorescence analysis of highly polar carboxylic acids using a column-switching system and fluorous scavenging derivatization. J. Sep. Sci. 2013, 36, 232-238. [CrossRef] [PubMed]

36. Michopoulos, F.; Whalley, N.; Theodoridis, G.; Wilson, I.D.; Dunkley, T.P.J.; Critchlow, S.E. Targeted profiling of polar intracellular metabolites using ion-pair-high performance liquid chromatography and -ultra high performance liquid chromatography coupled to tandem mass spectrometry: Applications to serum, urine and tissue extracts. J. Chromatogr. A 2014, 1349, 60-68. [CrossRef]

37. Guo, L.; Worth, A.J.; Mesaros, C.; Snyder, N.W.; Glickson, J.D.; Blair, I.A. Diisopropylethylamine/ hexafluoroisopropanol-mediated ion-pairing UHPLC-MS for phosphate and carboxylate metabolite analysis: Utility for studying cellular metabolism. Rapid Commun. Mass Spectrom. 2016, 30, 1835-1845. [CrossRef]

38. Buescher, J.M.; Moco, S.; Sauer, U.; Zamboni, N. Ultrahigh Performance Liquid Chromatography-Tandem Mass Spectrometry Method for Fast and Robust Quantification of Anionic and Aromatic Metabolites. Anal. Chem. 2010, 82, 4403-4412. [CrossRef]

39. Nemkov, T.; Sun, K.; Reisz, J.A.; Yoshida, T.; Dunham, A.; Wen, E.Y.; Wen, A.Q.; Roach, R.C.; Hansen, K.C.; Xia, Y.; et al. Metabolism of citrate and Other carboxylic acids in erythrocytes as a Function of Oxygen saturation and refrigerated storage. Front. Med. 2017, 4, 175. [CrossRef]

40. Fukushima, T.; Sone, Y.; Mitsuhashi, S.; Tomita, M.; Toyo'oka, T. Alteration of Kynurenic Acid Concentration in Rat Plasma Following Optically Pure Kynurenine Administration: A Comparative Study Between Enantiomers. Chirality 2009, 21, 468-472. [CrossRef]

41. Cseh, E.K.; Veres, G.; Szentirmai, M.; Nánási, N.; Szatmári, I.; Fülöp, F.; Vécsei, L.; Zádori, D. HPLC method for the assessment of tryptophan metabolism utilizing separate internal standard for each detector. Anal. Biochem. 2019, 574, 7-14. [CrossRef] [PubMed]

42. Brunius, C.; Vidanarachchi, J.K.; Tomankova, J.; Lundström, K.; Andersson, K.; Zamaratskaia, G. Skatole metabolites in urine as a biological marker of pigs with enhanced hepatic metabolism. Animal 2016, 10, 1734-1740. [CrossRef] [PubMed]

43. Kita, K.; Kawashima, Y.; Makino, R.; Namauo, T.; Ogawa, S.; Muraoka, H.; Fujimura, S. Detection of Two Types of Glycated Tryptophan Compounds in the Plasma of Chickens Fed Tryptophan Excess Diets. J. Poult. Sci. 2013, 50, 138-142. [CrossRef]

44. Makino, R.; Kita, K. Half-life of Glycated Tryptophan in the Plasma of Chickens. J. Poult. Sci. 2018, 55, 117-119. [CrossRef] [PubMed]

45. Valko-Rokytovská, M.; Hubková, B.; Birková, A.; Mašlanková, J.; Stupák, M.; Zábavníková, M.; Cižmárová, B.; Mareková, M. Specific Urinary Metabolites in Malignant Melanoma. Medicina 2019, 55, 145. [CrossRef] [PubMed] 
46. Tsunoda, M.; Mitsuhashi, K.; Masuda, M.; Imai, K. Simultaneous determination of 3,4-dihydroxyphenylacetic acid and homovanillic acid using high performance liquid chromatography-fluorescence detection and application to rat kidney microdialysate. Anal. Biochem. 2002, 307, 153-158. [CrossRef]

47. Huang, W.-H.; Hu, K.; Shao, L.; Chen, Y.; Zhang, W.; Zhou, H.-H.; Tan, Z.-R. Development and validation of a method for the determination of nicotinic acid in human plasma using liquid chromatography-negative electrospray ionization tandem mass spectrometry and its application to a bioequivalence study. Anal. Methods 2014, 6, 8258-8267. [CrossRef]

48. Al-Dirbashi, O.Y.; Santa, T.; Al-Qahtani, K.; Al-Amoudi, M.; Rashed, M.S. Analysis of organic acid markers relevant to inherited metabolic diseases by ultra-performance liquid chromatography/tandem mass spectrometry as benzofurazan derivatives. Rapid Commun. Mass Spectrom. 2007, 21, 1984-1990. [CrossRef]

49. Willacey, C.C.W.; Naaktgeboren, M.; Moreno, E.L.; Wegrzyn, A.B.; Es, D.; Karu, N.; Fleming, R.M.T.; Harms, A.C.; Hankemeier, T. LC-MS/MS analysis of the central energy and carbon metabolites in biological samples following derivatization by dimethylaminophenacyl bromide. J. Chromatogr. A 2019, 1608, 460413. [CrossRef]

50. Maestri, L.; Negri, S.; Ferrari, M.; Ghittori, S.; Fabris, F.; Danesino, P.; Imbriani, M. Determination of perfluorooctanoic acid and perfluorooctanesulfonate in human tisseues by liquid chromatography/single quadrupole mass spectrometry. Rapid Commun. Mass Spectrom. 2006, 20, 2728-2734. [CrossRef]

51. Wang, L.; Sun, H.; Yang, L.; He, C.; Wu, W.; Sun, S. Liquid chromatography/mass spectrometry analysis of perfluoroalkyl carboxylic acids and perfluorooctanesulfonate in bivalve shells: Extraction method optimization. J. Chromatogr. A 2010, 1217, 436-442. [CrossRef]

52. Kato, K.; Kalathil, A.A.; Patel, A.M.; Ye, X.; Calafat, A.M. Per- and polyfluoroalkyl substances and fluorinated alternatives in urine and serum by on-line solid phase extraction-liquid chromatogtaphy-tandem mass spectrometry. Chemosphere 2018, 209, 338-345. [CrossRef]

53. Gao, K.; Gao, Y.; Li, Y.; Fu, J.; Zhang, A. A rapid and fully automatic method for the accurate determination of a wide carbon-chain range of per- and polyfluoroalkyl substances (C4-C18) in human serum. J. Chromatogr. A 2016, 1471, 1-10. [CrossRef]

54. Lashgari, M.; Lee, H.K. Micro-solid phase extraction of perfluorinated carboxylic acids from human plasma. J. Chromatogr. A 2016, 1432, 7-16. [CrossRef] [PubMed]

55. Zhang, S.; Ji, Z.; Sun, Z.; Li, M.; Sheng, C.; Yue, M.; Yu, Y.; Chen, G.; You, J. Stable isotope labeling assisted liquid chromatography-tandem mass spectrometry for the analysis of perfluorinated carboxylic acids in serum samples. Talanta 2017, 166, 255-261. [CrossRef] [PubMed]

56. Liu, L.; She, J.; Zhang, X.; Zhang, J.; Tian, M.; Huang, Q.; Eqani, S.A.M.A.S.; Shen, H. Online background cleanup followed by high-performance liquid chromatography with tandem mass spectrometry for the analysis of perfluorinated compounds in human blood. J. Sep. Sci. 2015, 38, 247-253. [CrossRef]

57. Harrington, L.M. Analysis of perfluoroalkyl and polyfluoroalkyl substances in serum and plasma by solvent precipitation-isotope dilution-direct injection-LC/MS/MS. Anal. Methods 2017, 9, 473-481. [CrossRef]

58. Pailla, K.; Blonde-Cynober, F.; Aussel, C.; Bandt, J.; Cynober, L. Branched-Chain Keto-Acids and Pyruvate in Blood: Measurement by HPLC with Fluorimetric Detection and Changes in Older Subjects. Clin. Chem. 2000, 46, 848-853. [CrossRef]

59. Mühling, J.; Fuchs, M.; Campos, M.E.; Gonter, J.; Engel, J.M.; Sablotzki, A.; Menges, T.; Weiss, S.; Dehne, M.G.; Krüll, M.; et al. Quantitative determination of free intracellular $\alpha$-keto acids in neutrophils. J. Chromatogr. B 2003, 789, 383-392. [CrossRef]

60. Hattori, A.; Ito, T.; Tsunoda, M. Analysis of Branched-Chain Keto Acids in Cell Extracts by HPLC-Fluorescence Detection. Chromatography 2017, 38, 129-133. [CrossRef]

61. Fujiwara, T.; Hattori, A.; Ito, T.; Funatsu, T.; Tsunoda, M. Analysis of intracellular $\alpha$-keto acids by HPLC with fluorescence detection. Anal. Methods 2020, 12, 2555-2559. [CrossRef] [PubMed]

62. Olson, K.C.; Chen, G.; Lynch, C.J. Quantification of branched-chain keto acids in tissue by ultra fast liquid chromatography-mass spectrometry. Anal. Biochem. 2013, 439, 116-122. [CrossRef] [PubMed]

63. Noguchi, K.; Mizukoshi, T.; Miyano, H.; Yamada, N. Development of a New LC-MS/MS Method for the Quantification of Keto Acids. Chromatography 2014, 35, 117-123. [CrossRef]

64. Li, R.; Liu, P.; Liu, P.; Tian, Y.; Hua, Y.; Gao, Y.; He, H.; Chen, J.; Zhang, Z.; Huang, Y. A novel liquid chromatography tandem mass spectrometry method for simultaneous determination of branched-chain amino acids and branched-chain $\alpha$-keto acids in human plasma. Amino Acids 2016, 48, 1523-1532. [CrossRef] [PubMed] 
65. Poinsignon, V.; Mercier, L.; Nakabayashi, K.; David, M.D.; Lalli, A.; Penard-Lacronique, V.; Quivoron, C.; Saada, V.; Botton, S.D.; Broutin, S.; et al. Quantitation of isocitrate dehydrogenase (IDH)-induces D and $\mathrm{L}$ enantiomers of 2-hydroxyglutaric acid in biological fluids by a fully validated liquid tandem mass spectrometry method, suitable for clinical applications. J. Chromatogr. B 2016, 1022, 290-297. [CrossRef]

66. Cheng, Q.-Y.; Xiong, J.; Huang, W.; Ma, Q.; Ci, W.; Feng, Y.-Q.; Yuan, B.-F. Sensitive Determination of Onco-metabolites of D- and L-2-hydroxyglutarate Enantiomers by Chiral Derivatization Combined with Liquid Chromatography/Mass Spectrometry Analysis. Sci. Rep. 2015, 5, 15217. [CrossRef]

67. Petrikovics, I.; Thompson, D.E.; Rockwood, G.A.; Logue, B.A.; Martin, S.; Jayanna, P.; Yu, J.C.C. Organ-distribution of the metabolite 2-aminotiazoline-4-carboxylic acid in a rat model following cyanide exposure. Biomarkers 2011, 16, 686-690. [CrossRef]

68. Jackson, R.; Petrikovics, I.; Lai, E.P.C.; Yu, J.C.C. Molecularly imprinted polymer stir bar sorption extraction and electrospray ionization tandem mass spectrometry for determination of 2-aminothiazoline-4-carboxylic acid as a marker for cyanide exposure in forensic urine analysis. Anal. Methods 2010, 2, 552-557. [CrossRef]

69. Petrikovics, I.; Yu, J.C.C.; Thompson, D.E.; Jayanna, P.; Logue, B.A.; Nasr, J.; Bhandari, R.K.; Baskin, S.I.; Rockwood, G. Plasma persistence of 2-aminothiazoline-4-carboxylic acid in rat system determined by liquid chromatography tandem mass spectrometry. J. Chromatogr. B 2012, 891-892, 81-84. [CrossRef] [PubMed]

70. Luliński, P.; Giebułtowicz, J.; Wroczyński, P.; Maciejewska, D. A highly selective molecularly imprinted sorbent for extraction of 2-aminothiazoline-4-carboxylic acid - Synthesis, characterization and application in post-mortem whole blood analysis. J. Chromatogr. A 2015, 1420, 16-25. [CrossRef] [PubMed]

71. Giebułtowicz, J.; Sobiech, M.; Rużycka, M.; Luliński, P. Theoretical and experimental approach to hydrophilic interaction dispersive solid-phase extraction of 2-aminothiazoline-4-carboxylic acid from human post-mortem blood. J. Chromatogr. A 2019, 1587, 61-72. [CrossRef] [PubMed]

72. Giebułtowicz, J.; Rużycka, M.; Fudalej, M.; Krajewski, P.; Wroczynński, P. LC-MS/MS method development and validation for quantitative analysis of 2-aminothiazoline-4-carboxylic acid-A new cyanide exposure marker in post mortem blood. Talanta 2016, 150, 586-592. [CrossRef] [PubMed]

73. Reischl, R.J.; Bicker, W.; Keller, T.; Lamprecht, G.; Lindner, W. Occurrence of 2-methyltiazoline-4-carboxylic acid, a condensation product of cysteine and acetaldehyde, in human blood as a consequence of ethanol consumption. Anal. Bioanal. Chem. 2012, 404, 1779-1787. [CrossRef] [PubMed]

74. Chen, C.-W.; Shih, T.-S.; Li, C.-C.; Chou, J.-S. High Performance Liquid Chromatographic Determination of 2-Thiotiazolidine-4-Carboxylic Acid as a Marker of Occupational Exposure to Carbon Disulfide. Chromatographia 2001, 53, 665-668. [CrossRef]

75. Higashi, T.; Ichikawa, T.; Inagaki, S.; Min, J.Z.; Fukushima, T.; Toyo'oka, T. Simple and practical derivatization procedure for enhanced detection of carboxylic acids in liquid chromatography-electrospray ionization-tandem mass spectrometry. J. Pharm. Biomed. Anal. 2010, 52, 809-818. [CrossRef]

76. Mochizuki, Y.; Inagaki, S.; Suzuki, M.; Min, J.Z.; Inoue, K.; Todoroki, K.; Toyo'oka, T. A novel derivatization reagent possessing a bromoquinolinium structure for biological carboxylic acids in HPLC-ESI-MS/MS. J. Sep. Sci. 2013, 36, 1883-1889. [CrossRef]

77. Li, G.-L.; Chen, G.; Liu, Y.-Q.; Jing, N.-H.; You, J.-M. A sensitive and selective HPLC-FLD method with fluorescent labeling for simultaneous detection of bile acid and free fatty acid in human serum. J. Chromatogr. B 2012, 895-896, 191-195. [CrossRef]

78. Shi, Y.; Xiong, J.; Sun, D.; Liu, W.; Wei, F.; Ma, S.; Lin, R. Simultaneous quantification of the major bile acids in Artificial Calculus bovis by high-performance liquid chromatography with precolumn derivatization and its application in quality control. J. Sep. Sci. 2015, 38, 2753-2762. [CrossRef]

79. Kakiyama, G.; Muto, A.; Takei, H.; Nittono, H.; Murai, T.; Kurosawa, T.; Hofmann, A.F.; Pandak, W.M.; Bajaj, J.S. A simple and accurate HPLC method for fecal bile acid profile in healthy and cirrhotic subjects: Validation by GC-MS and LC-MS. J. Lipid. Res. 2014, 55, 978-990. [CrossRef]

80. Abdel-Khalik, J.; Crick, P.J.; Yutuc, E.; DeBarber, A.E.; Duell, P.B.; Steiner, R.D.; Laina, I.; Wang, Y.; Griffiths, W.J. Identification of 7 $\alpha$,24-dihydroxy-3-oxocholest-4-en-26-oic and 7 $\alpha, 25$-dihydroxy-3-oxocholest-4-en-26-oic acids in human cerebrospinal fluid and plasma. Biochimie 2018, 153, 86-98. [CrossRef]

81. Matsumoto, T.; Yamazaki, W.; Jo, A.; Ogawa, S.; Mitamura, K.; Ikegawa, S.; Higashi, T. A Method for Quantification of Tetrahydroglucocorticoid Glucuronides in Human Urine by LC/MS/MS with Isotope-coded Derivatization. Anal. Sci. 2018, 34, 1003-1009. [CrossRef] [PubMed] 
82. La Marca, G.; Casetta, B.; Zammarchi, E. Rapid determination of orotic acid in urine by a fast liquid chromatography/tandem mass spectrometric method. Rapid Commun. Mass Spectrom. 2003, 17, 788-793. [CrossRef]

83. Guo, K.; Li, L. High-Performance Isotope Labeling for Profiling Carboxylic Acid-Containing Metabolites in Biofluids by Mass Spectrometry. Anal. Chem. 2010, 82, 8789-8793. [CrossRef] [PubMed]

84. Zhao, S.; Li, L. Dansylhydrazine Isotope Labeling LC-MS for Comprehensive Carboxylic Acid Submetabolome Profiling. Anal. Chem. 2018, 90, 13514-13522. [CrossRef]

85. Mazza, M.; Pomponi, M.; Janiri, L.; Bria, P.; Mazza, S. Omega-3 fatty acids and antioxidants in neurological and psychiatric diseases: An overview. Prog. Neuropsychopharmacol. Biol. Psychiatry 2007, 31, 12-26. [CrossRef] [PubMed]

86. Lemaitre, R.N.; King, I.B.; Mozaffarian, D.; Sotoodehnia, N.; Rea, T.D.; Kuller, L.H.; Tracy, R.P.; Siscovick, D.S. Plasma Phospholipid Trans Fatty Acids, Fatal Ischemic Heart Disease, and Sudden Cardiac Death in Older Adults. Circulation 2006, 114, 209-215. [CrossRef] [PubMed]

87. Kurotani, K.; Karunapema, P.; Jayaratne, K.; Sato, M.; Hayashi, T.; Kajio, H.; Fukuda, S.; Hara, H.; Okazaki, O.; Jayatilleke, A.U.; et al. Circulating odd-chain saturated fatty acids were associated with arteriosclerosis among patients with diabetes, dyslipidemia, or hypertension in Sri Lanka but not Japan. Nutr. Res. 2018, 50, 82-93. [CrossRef]

88. Nikiforova, V.J.; Giesbertz, P.; Wiemer, J.; Bethan, B.; Looser, R.; Liebenberg, V.; Noppinger, P.R.; Daniel, H.; Rein, D. Glyoxylate, a New Marker Metabolite of Type 2 Diabetes. J. Diabetes Res. 2014, 2014, 685204. [CrossRef] [PubMed]

89. Hees, P.A.W.; Vinogradoff, S.I.; Edwards, A.C.; Godbold, D.L.; Jones, D.L. Low molecular weight organic acid adsorption in forest soils: Effects on soil solution concentrations and biodegradation rates. Soil Biol. Biochem. 2003, 35, 1015-1026.

90. Song, Y.; Xu, C.; Kuroki, H.; Liao, Y.; Tsunoda, M. Recent trends in analytical methods for the determination of amino acids in biological samples. J. Pharm. Biomed. Anal. 2018, 147, 35-49. [CrossRef]

91. Erhardt, S.; Schwieler, L.; Nilsson, L.; Linderholm, K.; Engberg, G. The kynurenic acid hypothesis of schizophrenia. Physiol. Behav. 2007, 92, 203-209. [CrossRef] [PubMed]

92. Dénes, Z.; Gábor, V.; Levente, S.; Péter, K.; László, V. Alzheimer's Disease: Recent Concepts on the Relation of Mitochondrial Disturbances, Excitotoxicity, Neuroinflammation, and Kynurenines. J. Alzheimer's Dis. 2018, 62, 523-547.

93. Hekster, F.M.; Laane, R.W.P.M.; Voogt, P. Environmental and Toxicity Effects of Perfluoroalkylated Substances. Rev. Environ. Contam. Toxicol. 2003, 179, 99-121. [PubMed]

94. Hattori, A.; Tsunoda, M.; Konuma, T.; Kobayashi, M.; Nagy, T.; Glushka, J.; Tayyari, F.; McSkimming, D.; Kannan, N.; Tojo, A.; et al. Cancer progression by reprogrammed BCAA metabolism in myeloid leukaemia. Nature 2017, 545, 500-504. [CrossRef]

95. Burlina, A.B.; Bonafé, L.; Zacchello, F. Clinical and Biochemical Approach to the Neonate with a Suspected Inborn Error of Amino Acid and Organic Acid Metabolism. Semin. Perinatol. 1999, 23, 162-173. [CrossRef]

96. Puliyel, J.M.; Bhambhani, V. Ketoacid levels may alter osmotonicity in diabetic ketoacidosis and precipitate cerebral edema. Arch. Dis. Child. 2003, 88, 364-367. [CrossRef]

Publisher's Note: MDPI stays neutral with regard to jurisdictional claims in published maps and institutional affiliations.

(C) 2020 by the authors. Licensee MDPI, Basel, Switzerland. This article is an open access article distributed under the terms and conditions of the Creative Commons Attribution (CC BY) license (http://creativecommons.org/licenses/by/4.0/). 